\title{
Role of oncogenic KRAS in the prognosis, diagnosis and treatment of colorectal cancer
}

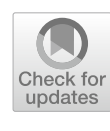

\author{
Gongmin Zhu ${ }^{1 \dagger}$, Lijiao Pei ${ }^{2 \dagger}$, Hongwei Xia ${ }^{1}$, Qiulin Tang ${ }^{1}$ and Feng $\mathrm{Bi}^{{ }^{1 *}}{ }^{\text {(i) }}$
}

\begin{abstract}
Colorectal cancer (CRC) is a heterogeneous disease at the cellular and molecular levels. Kirsten rat sarcoma (KRAS) is a commonly mutated oncogene in CRC, with mutations in approximately $40 \%$ of all CRC cases; its mutations result in constitutive activation of the KRAS protein, which acts as a molecular switch to persistently stimulate downstream signaling pathways, including cell proliferation and survival, thereby leading to tumorigenesis. Patients whose CRC harbors KRAS mutations have a dismal prognosis. Currently, KRAS mutation testing is a routine clinical practice before treating metastatic cases, and the approaches developed to detect KRAS mutations have exhibited favorable sensitivity and accuracy. Due to the presence of KRAS mutations, this group of CRC patients requires more precise therapies. However, KRAS was historically thought to be an undruggable target until the development of KRAS ${ }^{G 12 C}$ allele-specific inhibitors. These promising inhibitors may provide novel strategies to treat KRAS-mutant CRC. Here, we provide an overview of the role of KRAS in the prognosis, diagnosis and treatment of CRC.
\end{abstract}

Keywords: Colorectal cancer, KRAS, G12C, Prognosis, Targeted therapy, Combination therapy

\section{Introduction}

Colorectal cancer (CRC) ranks third in terms of new cases and represents the second leading cause of cancer-related death worldwide in 2018 [1]. Although many advanced management strategies, including improved surgical techniques and, modified adjuvant therapies, and have achieved favorable effects on the treatment of CRC, the mortality of CRC is still high on due to postoperative recurrence and metastasis [2]. CRC is widely considered a heterogeneous disease, with multiple gene alterations and numerous pathways involved in its pathogenesis [3]. The heterogeneity of CRC can be characterized by distinct clinical and pathological features, which lead to diverse prognoses and possibly account, at least in part, for resistance to treatment $[4,5]$. Currently, with the

\footnotetext{
*Correspondence: bifeng@scu.edu.cn

${ }^{\dagger}$ Gongmin Zhu and Lijiao Pei contributed equally to this work.

${ }^{1}$ Department of Abdominal Oncology, Cancer Center and Laboratory

of Molecular Targeted Therapy in Oncology, West China Hospital, Sichuan University, No.37 guoxue lane, Chengdu 610041, Sichuan Province, China

Full list of author information is available at the end of the article
}

rapid development and wide application of next generation sequencing (NGS), molecular profiles of many cancers have been revealed, including $\mathrm{CRC}$, which allows us to use these molecular biomarkers as both predictive and prognostic tools to manage patients with CRC [6].

Kirsten rat sarcoma (KRAS) is one of the most frequently mutated oncogenes in CRC, with approximately $40 \%$ of CRC patients harboring activating missense mutations in KRAS and most of them occurring at codons 12, 13 and 61 [7]. Patients with KRAS-mutant CRC have a poorer prognosis than those with KRASwild-type CRC, especially in the metastatic setting [8, 9]. Moreover, the upstream signal regulation of KRAS is interrupted by aberrant activation of the KRAS pathway, which results in resistance to receptor tyrosine kinase (RTK) inhibitors, such as monoclonal antibodies against epidermal growth factor receptor (EGFR) (cetuximab and panitumumab), in patients with KRAS-mutant CRC $[10,11]$. Because of the lack of an ideal small molecular binding pocket in the KRAS protein and its high affinity towards abundant guanosine triphosphate (GTP), the development of specific competitive drugs to inhibit

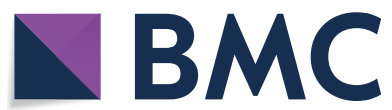

(C) The Author(s) 2021. Open Access This article is licensed under a Creative Commons Attribution 4.0 International License, which permits use, sharing, adaptation, distribution and reproduction in any medium or format, as long as you give appropriate credit to the original author(s) and the source, provide a link to the Creative Commons licence, and indicate if changes were made. The images or other third party material in this article are included in the article's Creative Commons licence, unless indicated otherwise in a credit line to the material. If material is not included in the article's Creative Commons licence and your intended use is not permitted by statutory regulation or exceeds the permitted use, you will need to obtain permission directly from the copyright holder. To view a copy of this licence, visit http://creativecommons.org/licenses/by/4.0/. The Creative Commons Public Domain Dedication waiver (http://creativeco mmons.org/publicdomain/zero/1.0/) applies to the data made available in this article, unless otherwise stated in a credit line to the data. 
KRAS-driven oncogenesis has eluded the field. Despite the effort, KRAS is still considered 'undruggable', and treatment of KRAS-mutant CRC remains a challenge. In recent years, preliminary results from early clinical trials show that direct inhibition of KRAS ${ }^{\mathrm{G} 12 \mathrm{C}}$ has become possible, which may provide a novel targeted treatment for a number of patients with advanced CRC [12].

In this review, we briefly describe the role of KRAS mutational status in CRC. Then, we summarize the current techniques used to detect KRAS mutations. Third, we focus on recent strategies to directly or indirectly inhibit KRAS in CRC, especially breakthrough therapies that target KRAS ${ }^{\mathrm{G} 12 \mathrm{C}}$, and detail the clinical use of these inhibitors. Finally, we suggest future directions for the treatment of KRAS-mutant CRC.

\section{KRAS molecular structure and function}

The KRAS gene encodes a GTP/guanosine diphosphate (GDP)-binding protein that belongs to the guanosine triphosphatase (GTPase) RAS family. The KRAS gene alternatively forms two splice variants (KRAS $4 A$ and $K R A S 4 B$ ) using different exons 4. Among them, KRAS $4 B$ has long been considered the main isoform due to its wide and high expression in human cancers [13, 14]. However, in recent years, KRAS $4 A$ was also proven to be ubiquitously expressed in various cancers and able to increase the adaptability of tumor cells under stress [15, 16]. The KRAS protein has a molecular weight of $21 \mathrm{kDa}$, and is made up of six beta strands and five alpha helices, which form two major domains: the G-domain and the C-terminal $[17,18]$. The $\mathrm{G}$ domain is highly conserved and contains switch I and switch II loops, which are responsible for GDP-GTP exchange [19]. The C-terminal, a hypervariable region including the $\mathrm{CAAX}(\mathrm{C}=$ cysteine, $\mathrm{A}=$ any aliphatic amino acid, $\mathrm{X}=$ any amino acid) motif, is the target for various posttranslational modifications and plays a vital role in newly synthesized and processed KRAS trafficking, as well as final plasma membrane anchoring $[13,19]$.

The KRAS protein acts as a "molecular switch" that cycles between a GDP-bound inactive state and a GTPbound active state [20]. Although the KRAS protein harbors both intrinsic nucleotide exchange and GTP hydrolysis, its cellular signaling state arises from activation by guanine exchange factors (GEFs), such as son of sevenless (SOS) and Ras guanyl nucleotide-releasing protein, which catalyze GTP loading and deactivation by GTPase activating proteins (GAPs), such as p120GAP and neurofibromin (NF1), which stimulate GTP hydrolysis [21]. GTP binding to KRAS facilitates the binding of effectors to trigger several downstream pathways, including the rapidly accelerated fibrosarcoma (RAF)-mitogen-activated protein kinase kinase (MEK)-extracellular signal-regulated kinase (ERK) and phosphatidylinositol 3-kinase (PI3K)-protein kinase B (AKT)-mechanistic target of rapamycin (mTOR) pathways, which promote cell growth and survival (Fig. 1). In contrast, GDP-bound KRAS loses its activity and prevents its persistent signal transduction activation.

\section{KRAS mutations and their roles in CRC KRAS mutation subtypes}

$K R A S$ is one of the most frequently mutated oncogenes across all malignancies. The prevalence of KRAS mutations is approximately $40 \%$ in CRC cases (Fig. 2a). Once KRAS mutations occur, the hydrolysis of GTP is disrupted and/or nucleotide exchange is enhanced, and then KRAS accumulates in an active state, contributing to continuous activation of downstream signaling pathways, thereby promoting tumor cell proliferation. Therefore, colorectal tumors bearing KRAS mutations are associated with advanced disease status, poor tumor differentiation, distant metastasis and inferior survival in patients $[9,22]$.

In CRC, KRAS mutations are most associated with right-sided colon tumors and approximately $85 \%$ of KRAS mutations occur in one of three major hotspots (codons 12, 13 and 61) [23, 24]. Among them, codon 12 mutation is dominant, accounting for approximately $65 \%$ of all KRAS alleles. Moreover, G12D (glycine 12 to aspartic acid) and G12V (glycine 12 to valine) are the two most common subtypes in CRC, unlike non-small-cell lung cancer (NSCLC) where G12C (glycine 12 to cysteine) is the most common subtype. The frequency and distribution of KRAS mutations for CRC are shown in Fig. 2a. G12 and G13 are located on the P loop, which is required for stabilizing the nucleotide in an active state. Generally, mutations in codon 12 diminish both inherent and GAP-mediated hydrolysis without affecting the rate of nucleotide exchange, except for $K R A S^{G 12 C}$, which exhibits GTPase activity similar to that of wild type (Fig. 2b) [25]. In contrast, codon 13 mutations not only decrease hydrolysis but also elevate intrinsic exchange activity (Fig. 2b) [26]. Q61 is located at the N-terminus of switch II and participates in the conformational changes related to this region during the interconversion between structural states. Mutations in codon 61 promote GDP-GTP exchange and simultaneously disrupt GTP hydrolysis (Fig. 2b). Moreover, among all KRAS alleles, Q61 mutants have the lowest hydrolysis rate [25].

\section{Prognostic and predictive value of KRAS mutations}

Due to the diversity of KRAS alleles in CRC, patients harboring different KRAS mutation variants may have a distinct prognosis. Several independent analyses of large cohorts indicated that KRAS codon 12 mutations rather 


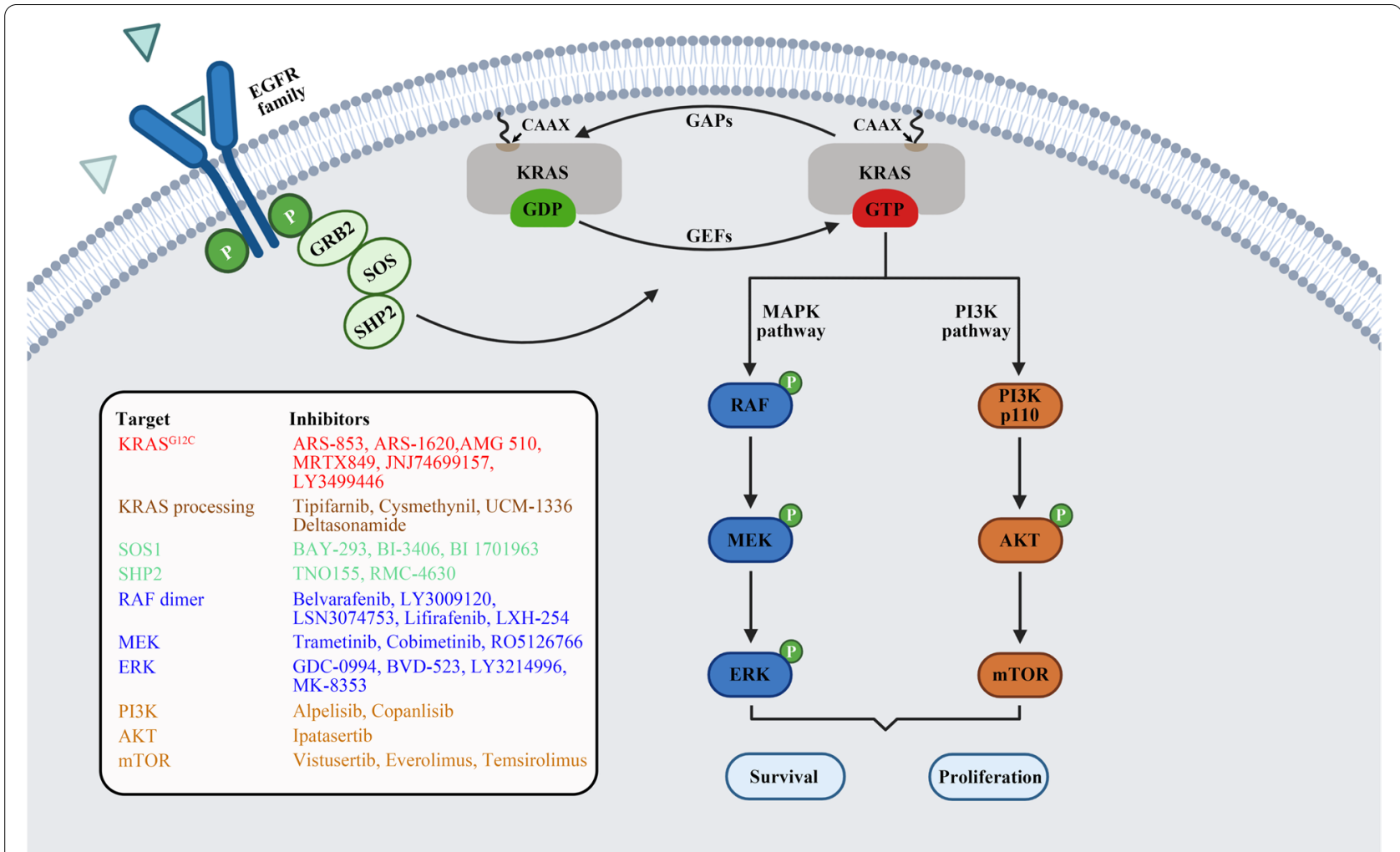

Fig. 1 KRAS signaling pathway and relevant inhibitors of each node. After the activation of receptor tyrosine kinase, GRB2 combines with the guanine nucleotide exchange factor SOS and then interacts with KRAS protein that is attached to the cell membrane, thereby promoting KRAS activation. Intrinsic KRAS GTP-GDP cycling is regulated by GEFs and GAPs. Once KRAS is mutated, this cycle is disrupted, allowing mutant KRAS protein to accumulate in an active state and thereby persistently activating downstream MAPK and PI3K signaling cascade, resulting in cell proliferation and survival. Various KRAS inhibitors listed in the box were developed to target each node of the KRAS signaling pathway and then evaluated in preclinical or clinical studies. Created with BioRender.com

than codon 13 mutations were associated with dismal prognosis compared with KRAS wild-type cases. When the prognosis was further classified by specific point mutations, G12V and G12C were proven to be correlated with worse overall survival (OS) [27, 28]. Likewise, a pooled analysis including 1239 patients with metastatic CRC from five randomized trials indicated that patients who harbored the $K R A S^{G 12 C}$ mutation were associated with worse OS than patients with nonmutated tumors [29]. The reason for the distinction of prognosis is still not well understood. Different biological behaviors of individual mutation variants, such as differential activation of the KRAS downstream effect pathways, have been suggested [30]. However, conflicting views have been proposed, and more frequent $K R A S$ variants, such as G12D and G12V, were reported to lack obvious impacts on OS in univariate and multivariate Cox analyses [29]. The clinical data vary among studies, and this may be caused by cohort size, tumor subtyping, tumor staging, genetic background, and even the different methods of collecting mutational data, which makes them difficult to explain and validate.

Chemotherapy based on 5-fluorouracil, leucovorin, and oxaliplatin (FOLFOX) remains the standard firstline treatment for advanced CRC. KRAS mutations, especially G12D, are predictive of an inferior response to chemotherapy and a high risk of recurrence [31]. Moreover, KRAS mutations are also robust predictors for the efficacy of treatment with EGFR inhibitors in patients with CRC. Monoclonal antibodies targeting ERFR were proven to benefit CRC patients who were refractory to other therapies [32]. However, patients whose tumors harbor KRAS mutations in exons 2 (codons 12 and 13), 3 (codons 59 and 61), and 4 (codons 117 and 146) cannot derive benefit from treatment with anti-EGFR therapy, which means that KRAS mutations are negative biomarkers for this therapy [33-35]. In fact, not all $K R A S$ alleles confer resistance to anti-EGFR therapy. Previous retrospective analyses indicated that CRC patients with the KRAS $S^{G 13 D}$ mutation benefited from first-line chemotherapy plus cetuximab, although 
$\mathbf{a}$
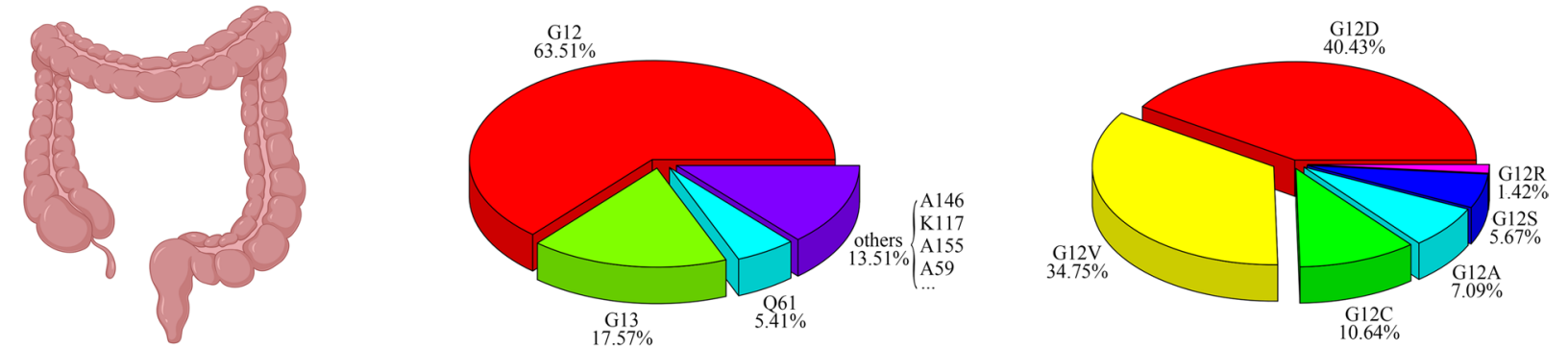

KRAS $40 \%$

b
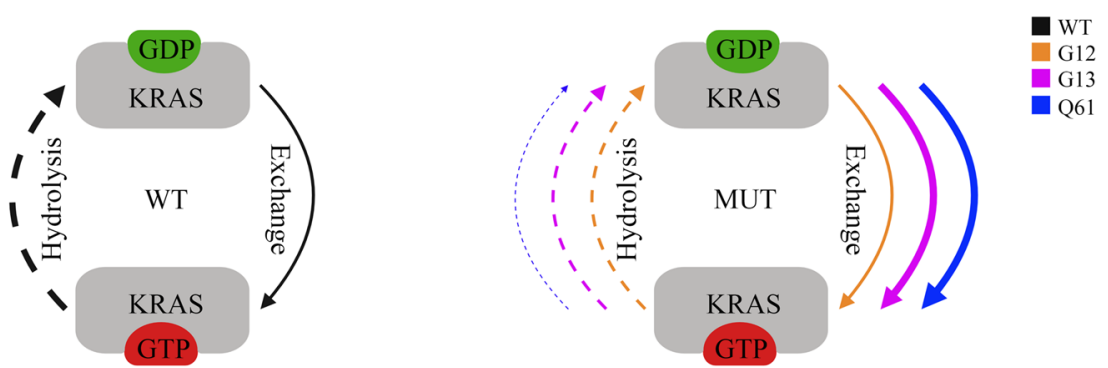

Fig. 2 Frequency and distribution of KRAS mutations in CRC and the biochemical features of mutant KRAS proteins. a Percentage of KRAS mutation in CRC and the diversity of KRAS alleles. Data acquired from The Cancer Genome Atlas (pan-Cancer) from cBioPortal. b Overview of generalized biochemical change of hydrolysis and guanine exchange following mutations in codons 12 (orange), 13 (purple) or, 61 (blue). The dashed line indicates hydrolysis and the solid line indicates guanine exchange, with the thicker line indicating faster rates and vice versa for slower rates.

Created with BioRender.com. WT, wild type; MUT, mutant type

the absolute values of response rate, progression-free survival (PFS) and OS were still below those of patients with KRAS wild-type tumors [36, 37].

\section{Identification of KRAS mutations in CRC}

Given that oncogenic point mutation of KRAS is a common event during CRC and plays a critical role in prognostic evaluation and therapeutic decision-making, KRAS mutations should routinely be tested for in the diagnosis of CRC. A variety of laboratory methods are available for the detection of KRAS mutations in biological samples, including formalin-fixed paraffin-embedded (FFPE) tissues, fresh tumor tissues, fine-needle aspiration (FNA) materials and cytology and body fluids [38-40]. Detection methods and their sensitivities are summarized in Table 1.

\section{Routine laboratory methods}

Currently, direct sequencing, namely, polymerase chain reaction (PCR) followed by dideoxy sequencing, is still

Table 1 Summary of the main KRAS detection methods

\begin{tabular}{|c|c|c|c|}
\hline Techniques & Range of detection & Sensitivity $^{a}$ & References \\
\hline Direct sequencing & All mutations in the interested region & $10-30 \%$ & {$[41]$} \\
\hline TheraScreen KRAS kit & 7 KRAS mutations in codons 12 and 13 & Approximately 1\% & {$[42,43]$} \\
\hline StripAssay & 10 KRAS mutations in codons 12 and 13 & $1 \%$ & {$[44,45]$} \\
\hline SNaPshot & 12 KRAS mutations in codons 12 and 13 & $10 \%$ & {$[44,45]$} \\
\hline Cobas & 19 KRAS mutations in codons 12,13 and 61 & Approximately 1\% & {$[46]$} \\
\hline Next generation sequencing & All clinical relevant KRAS mutations & $1-6 \%$ & {$[47,48]$} \\
\hline Droplet digital PCR & 7 KRAS mutations in codons 12 and 13 & $0.01-0.05 \%$ & {$[48,49]$} \\
\hline BEAMing & 16 KRAS mutations in codons $12,13,59,61,117$ and 146 & $0.01 \%$ & {$[48,50]$} \\
\hline
\end{tabular}

Abbreviations: BEAM beads, emulsion, amplification, magnetics

a Sensitivity is the mutant to wild-type ratio showed as a percentage 
the gold standard method for detecting mutations. This method is able to detect all mutations in the region of interest, but it requires a high allele frequency of mutation $(10-30 \%)$ to meet the level of detection, suggesting that it may not be appropriate for clinical application due to its sensitivity $[41,42]$.

TheraScreen KRAS kit (Qiagen), a test based on amplification refractory mutation system (ARMS) technology, is the first clinically validated and FDA-approved kit widely used to evaluate tumor-specific mutations in patients with CRC [43]. This kit detects seven mutations in codons 12 and 13 in the KRAS oncogene, and has higher sensitivity and specificity than direct sequencing. In addition, this kit has been applied to phase III clinical trials for metastatic CRC [11, 44]. StripAssay (Vienna Labs) based on mutant-enriched PCR followed by reverse hybridization also has a much lower detection threshold than direct sequencing, and it can detect 10 of the most common mutations (eight in codon 12 and two in codon 13). However, its flexibility is poor, and the cost is much higher than that of direct sequencing. Another technique, SNaPshot, is not as sensitive as StripAssay, but it can detect 12 mutations in codons 12 and 13, and it is more flexible and cheaper than StripAssay [45]. The TaqMelt PCR assay Cobas (Roche) can detect 19 KRAS mutations in codons 12, 13 and 61 and is more sensitive than the TheraScreen assay. Moreover, this assay is highly reproducible $(>98 \%)$ and has a rapid turnaround time (1 day) [46].

However, the limitation of these kits is the inability to detect uncommon mutated alleles, and patients with these mutations hardly benefit from anti-EGFR therapies. Next generation sequencing, due to its great sensitivity and entire exon sequencing, can identify all clinically relevant KRAS mutations [47]. NGS is based on the original concept of pyrosequencing but uses fluorescence markers or $\mathrm{pH}$ measurements to determine the sequence of DNA nucleotides. This technology is now well established and is routinely used to analyze mutations in solid and liquid (hematologic) samples in many laboratories. Due to the high cost of NGS per sample, NGS panels for CRC usually analyze mutational hotspots in various oncogenes, which provides broader views for the occurrence and progression of tumors and is more likely to find druggable targets than only detect KRAS [51].

\section{KRAS mutation assay in liquid biopsy samples}

Currently, the detection of KRAS mutations is most commonly carried out in tumor tissue, especially FFPE tumor tissues. Although these analyses based on tumor tissues acquire satisfactory results in terms of sensitivity and specificity, they rely heavily on the quality and quantity of the tumor samples and have a slow turnaround time
[52], which may not meet the urgent requirement of patients in first-line treatment for metastatic CRC [53]. Liquid biopsy, an emerging analytical technique, has the advantages of minimal invasiveness, rapid detection, and the ability to present comprehensive molecular characteristics of the disease, enabling early diagnosis, evaluation of the response to molecular targeted therapies and early exploration of the potential resistance mechanisms of cancer cells [54]. Likewise, the clinical application of liquid biopsy has also been developed in each clinical stage of CRC, of which circulating tumor DNA (ctDNA) is the most clinically advanced. ctDNA is cell-free DNA (cfDNA) released into circulation by tumor cells and reflects mutations specific to tumor cells [55]. It can be isolated from plasma but only accounts for a small part of the total cfDNA isolated from plasma. For this reason, highly sensitive techniques are required for the ctDNA test. This requirement is currently met by the development of PCR-based methods, such as allele-specific quantitative PCR-based Intplex technology and emulsion PCR techniques (ddPCR and BEAMing), and the advent of NGS $[48-50,52]$. Therefore, it is no surprise that KRAS mutation detection in blood from patients with $\mathrm{CRC}$ is gaining momentum.

Nevertheless, despite the use of highly sensitive technology, circulating KRAS mutation detection does not perfectly reflect the mutation burden of the primary tumor from which it originated. One might speculate that tumor cells at an early stage cannot release adequate ctDNA or that the concentration of ctDNA is low and its quality degraded. In addition, several studies have reported the discordance between ctDNA and tissues in examining KRAS mutations in CRC patients [56, 57]. On the one hand, ctDNA tests are able to detect shed DNA from various tumor sites in theory, whereas tissue biopsy only finds alterations at the specific site of sampling. On the other hand, the difference in sensitivity of nucleic acid processing and analytical technologies may also lead to discordance.

Overall, liquid biopsy is a promising field in CRC, whereas the clinical use of this approach still requires large prospective studies with adequate cohorts of patients and standardized methods of analysis. But anyway, one point is clear that liquid biopsy KRAS testing can provide complementary information to the tissue tests [54].

\section{KRAS targeting therapy in CRC}

\section{Historical perspectives on KRAS targeting therapy}

For a long time, KRAS has been considered an "undruggable" target due to the specific characteristics of KRAS its molecular structure. The KRAS protein is a small protein with a relatively smooth surface. In addition to 
the GTP/GDP binding pocket, the KRAS protein does not provide enough pockets for small molecular inhibitor binding [58]. Moreover, the extremely high affinity of KRAS for GTP and the high cellular concentrations of GTP make it almost impossible to develop a competitive small molecule inhibitor [58]. Additionally, indiscriminate inhibition of both wild-type and mutant KRAS may lead to potential toxicity [59]. Therefore, inhibiting KRAS directly is a great challenge for KRASmutant tumor treatment.

Similarly, approaches that indirectly target KRAS, including the inhibition of nucleotide exchange, processing, membrane localization and molecules in the signaling pathway, have not been very effective clinically. Multiple positive and negative feedback loops implicated in the KRAS signaling network enable easy rebound of the therapeutic $[60,61]$. In addition, the mutant KRAS protein can activate other cancer-related cellular processes, such as cell Warburg metabolism to maintain tumor growth, which results in the low or absent inhibitory effect of the indirect targeting of KRAS [62].

Although KRAS-targeting therapy is still an enormous challenge, various attempts have been made to discover small molecules to overcome this problem. Here, we highlight the latest efforts in targeting mutant KRAS and summarize the relevant clinical trials conducted in CRC (Tables 2 and 3) and the characteristics of some of these drugs (Additional file 1: Table S1).

\section{Strategies to target KRAS directly Covalent inhibitors targeting KRAS ${ }^{\mathrm{G} 12 \mathrm{C}}$}

Recently, the discovery of inhibitors that selectively target KRAS ${ }^{\mathrm{G} 12 \mathrm{C}}$ while preserving wild-type or other mutant KRAS to circumvent the toxicity caused by inhibition of all KRAS isoforms was a breakthrough in this field of research [63]. KRAS ${ }^{\mathrm{G} 12 \mathrm{C}}$ arises from a glycineto-cysteine substitution at codon 12 , and the thiol group

Table 2 Single-agent therapies in clinical trials

\begin{tabular}{|c|c|c|c|c|c|c|}
\hline Inhibitor & Biomarker & Cancer type & CRC patients enrollment & Phase & NCT number & Status \\
\hline \multicolumn{7}{|l|}{$\mathrm{KRAS}^{\mathrm{G} 12 \mathrm{C}}$ inhibitors } \\
\hline AMG 510 & $K R A S^{G 12 C}$ mutation & Advanced solid tumors & Enrolled & $|/| \mid$ & NCT03600883 & Recruiting \\
\hline MRTX849 & $K R A S^{G 12 C}$ mutation & Advanced solid tumors & Enrolled & $|/| \mid$ & NCT03785249 & Recruiting \\
\hline JNJ-74699157 & KRAS $S^{G 12 C}$ mutation & Advanced solid tumors & Enrolled & 1 & NCT04006301 & Completed \\
\hline LY3499446 & KRAS ${ }^{G 12 C}$ mutation & Advanced solid tumors & Enrolled & $|/| \mid$ & NCT04165031 & Terminated \\
\hline \multicolumn{7}{|l|}{ SOS inhibitors } \\
\hline Bl 1701963 & KRAS mutations & Advanced solid tumors & Not mentioned & 1 & NCT04111458 & Recruiting \\
\hline \multicolumn{7}{|l|}{ SHP2 inhibitors } \\
\hline RMC-4630 & $\begin{array}{l}\text { Mutations that hyperactive } \\
\text { the RAS-MAPK pathway }\end{array}$ & $\begin{array}{l}\text { Relapsed or refractory solid } \\
\text { tumors }\end{array}$ & Not mentioned & 1 & NCT03634982 & Recruiting \\
\hline \multicolumn{7}{|l|}{ RAF inhibitors } \\
\hline LY3009120 & $\begin{array}{l}\text { BRAF, NRAS or KRAS muta- } \\
\text { tions }\end{array}$ & $\begin{array}{l}\text { Advanced or metastatic } \\
\text { solid tumors }\end{array}$ & Enrolled & 1 & NCT02014116 & Terminated \\
\hline BGB-283 & $\begin{array}{l}\text { BRAF, NRAS or KRAS muta- } \\
\text { tions }\end{array}$ & Advanced solid tumors & Enrolled & 1 & NCT02610361 & Completed \\
\hline \multicolumn{7}{|l|}{ ERK inhibitors } \\
\hline GDC-0994 & BRAF or KRAS mutations & $\begin{array}{l}\text { Advanced or metastatic } \\
\text { solid tumors }\end{array}$ & Enrolled & 1 & NCT01875705 & Completed \\
\hline BVD-523 & $\begin{array}{l}\text { NRAS, HRAS, KRAS, BRAF, MEK } \\
\text { or ERK mutations }\end{array}$ & $\begin{array}{l}\text { Advanced MAPK pathway- } \\
\text { altered malignancies }\end{array}$ & Enrolled & 1 & NCT04566393 & Available \\
\hline \multicolumn{7}{|l|}{ Adoptive cell therapies } \\
\hline Anti-KRAS G12D mTCR & $\begin{array}{l}\text { HLA-A }^{*} 11: 01 \text { positive } \\
\text { KRAS }^{G 12 D} \text { mutation }\end{array}$ & Advanced solid tumors & Enrolled & $|/| \mid$ & NCT03745326 & Suspended \\
\hline Anti-KRAS G12V mTCR & $\begin{array}{l}\text { HLA-A*11:01 positive } \\
\text { KRAS }^{* 12 D} \text { mutation }\end{array}$ & Advanced solid tumors & Enrolled & $|/| \mid$ & NCT03190941 & Suspended \\
\hline \multicolumn{7}{|l|}{ Cancer vaccines } \\
\hline TG02 & $\begin{array}{l}\text { KRAS exon 2, codon } 12 \text { or } \\
13 \text { mutation }\end{array}$ & Rectal cancer & Enrolled & 1 & NCT02933944 & Terminated \\
\hline mRNA-5671 & $\begin{array}{l}K^{K} A S^{G 12 D}, K^{\prime} R A S^{G 12 V}, K^{\prime} A S^{G 12 C} \\
K^{\prime} A S^{G 13 D} \text { mutation }\end{array}$ & $\begin{array}{l}\text { NSCLC, non-MSI-HCRC, } \\
\text { PDAC }\end{array}$ & Enrolled & 1 & NCT03948763 & Recruiting \\
\hline
\end{tabular}


Table 3 Combination therapies in clinical trials

\begin{tabular}{|c|c|c|c|c|c|c|}
\hline Inhibitor & Biomarker & Cancer type & $\begin{array}{l}\text { CRC patients } \\
\text { enrollment }\end{array}$ & Phase & NCT number & Status \\
\hline \multicolumn{7}{|l|}{$\mathrm{KRAS}^{\mathrm{G} 12 \mathrm{C}}$ combinations } \\
\hline $\begin{array}{l}\text { AMG } 510 \text { and panitu- } \\
\text { mumab and FOLFIRI } \\
\text { regimen }\end{array}$ & $K_{R A S^{G 12 C}}$ mutation & Advanced solid tumors & Enrolled & $\mathrm{lb} / \mathrm{II}$ & NCT04185883 & Recruiting \\
\hline $\begin{array}{l}\text { AMG } 510 \text { and trametinib } \\
\text { and panitumumab }\end{array}$ & $K_{R A S^{G 12 C}}$ mutation & Advanced solid tumors & Enrolled & $\mathrm{lb} / \mathrm{II}$ & NCT04185883 & Recruiting \\
\hline $\begin{array}{l}\text { AMG } 510 \text { and MVASI }{ }^{\circledR} \\
\text { (bevacizumab-awwb) } \\
\text { and FOLFIRI or FOLFOX } \\
\text { regimen }\end{array}$ & KRAS ${ }^{G 12 C}$ mutation & Advanced solid tumors & Enrolled & $\mathrm{lb} / \mathrm{II}$ & NCT04185883 & Recruiting \\
\hline MRTX849 and TN0155 & KRAS ${ }^{G 12 C}$ mutation & Advanced solid tumors & Enrolled & $\|$ & NCT04330664 & Recruiting \\
\hline $\begin{array}{l}\text { MRTX849 and cetuxi- } \\
\text { mab }\end{array}$ & $K_{R A S^{G 12 C}}$ mutation & $\begin{array}{l}\text { Advanced or metastatic } \\
\text { CRC }\end{array}$ & Enrolled & III & NCT04793958 & Recruiting \\
\hline $\begin{array}{l}\text { MRTX849 and } \mathrm{mFOL-} \\
\text { FOX6 regimen }\end{array}$ & $K_{R A S^{G 12 C}}$ mutation & $\begin{array}{l}\text { Advanced or metastatic } \\
\text { CRC }\end{array}$ & Enrolled & III & NCT04793958 & Recruiting \\
\hline $\begin{array}{l}\text { MRTX849 and FOLFIRI } \\
\text { regimen }\end{array}$ & $K_{R A S^{G 12 C}}$ mutation & $\begin{array}{l}\text { Advanced or metastatic } \\
\text { CRC }\end{array}$ & Enrolled & III & NCT04793958 & Recruiting \\
\hline \multicolumn{7}{|c|}{ SOS inhibitors combinations } \\
\hline $\begin{array}{l}\text { Bl } 1701963 \text { and } \\
\text { trametinib }\end{array}$ & KRAS mutations & Advanced solid tumors & Not mentioned & I & NCT04111458 & Recruiting \\
\hline \multicolumn{7}{|c|}{ SHP2 inhibitors combinations } \\
\hline $\begin{array}{l}\text { RMC-4630 and } \\
\text { LY3214996 }\end{array}$ & KRAS mutations & $\begin{array}{l}\text { Advanced or metastatic } \\
\text { solid tumors }\end{array}$ & Enrolled & 1 & NCT04916236 & Not yet recruiting \\
\hline TNO155 and JDQ443 & KRAS ${ }^{G 12 C}$ mutation & Advanced solid tumors & Enrolled & $\mathrm{lb} / \mathrm{ll}$ & NCT04699188 & Recruiting \\
\hline \multicolumn{7}{|c|}{ RAF-MEK-ERK inhibitors combinations } \\
\hline $\begin{array}{l}\text { HM95573 and cobi- } \\
\text { metinib }\end{array}$ & RAS or RAF mutations & $\begin{array}{l}\text { Advanced or metastatic } \\
\text { solid tumors }\end{array}$ & Enrolled & I & NCT03284502 & Recruiting \\
\hline $\begin{array}{l}\text { GDC-0994 and cobi- } \\
\text { metinib }\end{array}$ & None & $\begin{array}{l}\text { Advanced or metastatic } \\
\text { solid tumors }\end{array}$ & Enrolled & $\mathrm{lb}$ & NCT02457793 & Completed \\
\hline $\begin{array}{l}\text { MK-8353 and pembroli- } \\
\text { zumab }\end{array}$ & None & Advanced solid tumors & Enrolled & $\mathrm{lb}$ & NCT02972034 & Active, not recruiting \\
\hline \multicolumn{7}{|c|}{ Cancer vaccines combinations } \\
\hline $\begin{array}{l}\text { TG02 and pembroli- } \\
\text { zumab }\end{array}$ & $\begin{array}{l}\text { KRAS exon 2, codon } 12 \\
\text { or } 13 \text { mutation }\end{array}$ & Rectal cancer & Enrolled & 1 & NCT02933944 & Terminated \\
\hline $\begin{array}{l}\text { mRNA-5671 and pem- } \\
\text { brolizumab }\end{array}$ & $\begin{array}{l}K^{\prime} A S^{G 12 D}, K^{G} S^{G 12 V} \\
K^{G A S^{G 12 C}}, K^{\prime} R A S^{G 13 D^{\prime}} \\
\text { mutation }\end{array}$ & $\begin{array}{l}\text { NSCLC, non-MSI-HCRC, } \\
\text { PDAC }\end{array}$ & Enrolled & I & NCT03948763 & Recruiting \\
\hline
\end{tabular}

Abbreviations: CRC colorectal cancer, NSCLC non-small cell lung cancer, PDAC pancreatic ductal adenocarcinoma, MSI-H microsatellite instability-high, FOLFOX 5-fluorouracil, leucovorin, and oxaliplatin, FOLFIRI: 5-fluorouracil, leucovorin, and irinotecan. Data acquired from ClinicalTrials.gov

in the cysteine residue is an attractive target for covalent inhibitors. In contrast, wild-type KRAS is not inhibited by this covalent approach due to the lack of cysteine in the active site. The first series of compounds targeting $\mathrm{KRAS}^{\mathrm{G} 12 \mathrm{C}}$ was developed by Shokat and colleagues. These compounds covalently bind to the mutant cysteine residue and occupy a new allosteric pocket behind switch-II, namely, the switch-II pocket, when KRAS ${ }^{\mathrm{G} 12 \mathrm{C}}$ is in its GDP-bound state [63]. Then, these compounds change the nucleotide preference of KRAS from GTP to GDP, which contributes to the accumulation of KRAS in the inactive state. Moreover, these compounds attenuate associations with regulatory proteins and effectors such as the exchange factors SOS and RAF, and thereby prevent signaling by KRAS. However, the most potent compound developed by Shokat and colleagues (Compound 12) was reported to have low pharmacological properties [64].

Subsequently, numerous studies have continued to improve the efficacy of KRAS ${ }^{\mathrm{G} 12 \mathrm{C}}$ inhibition, and a series of novel KRAS ${ }^{\mathrm{G} 12 \mathrm{C}}$ inhibitors have been developed, including ARS-853 [64], ARS-1620 [65], AMG 510 [66] and MRTX859 [67, 68] (Fig. 3). Among them, AMG 510 was the first compound to enter clinical trials and showed remarkable single-agent efficacy in a phase I trial, especially in NSCLC (NCT03600883; Table 2). Recently, 


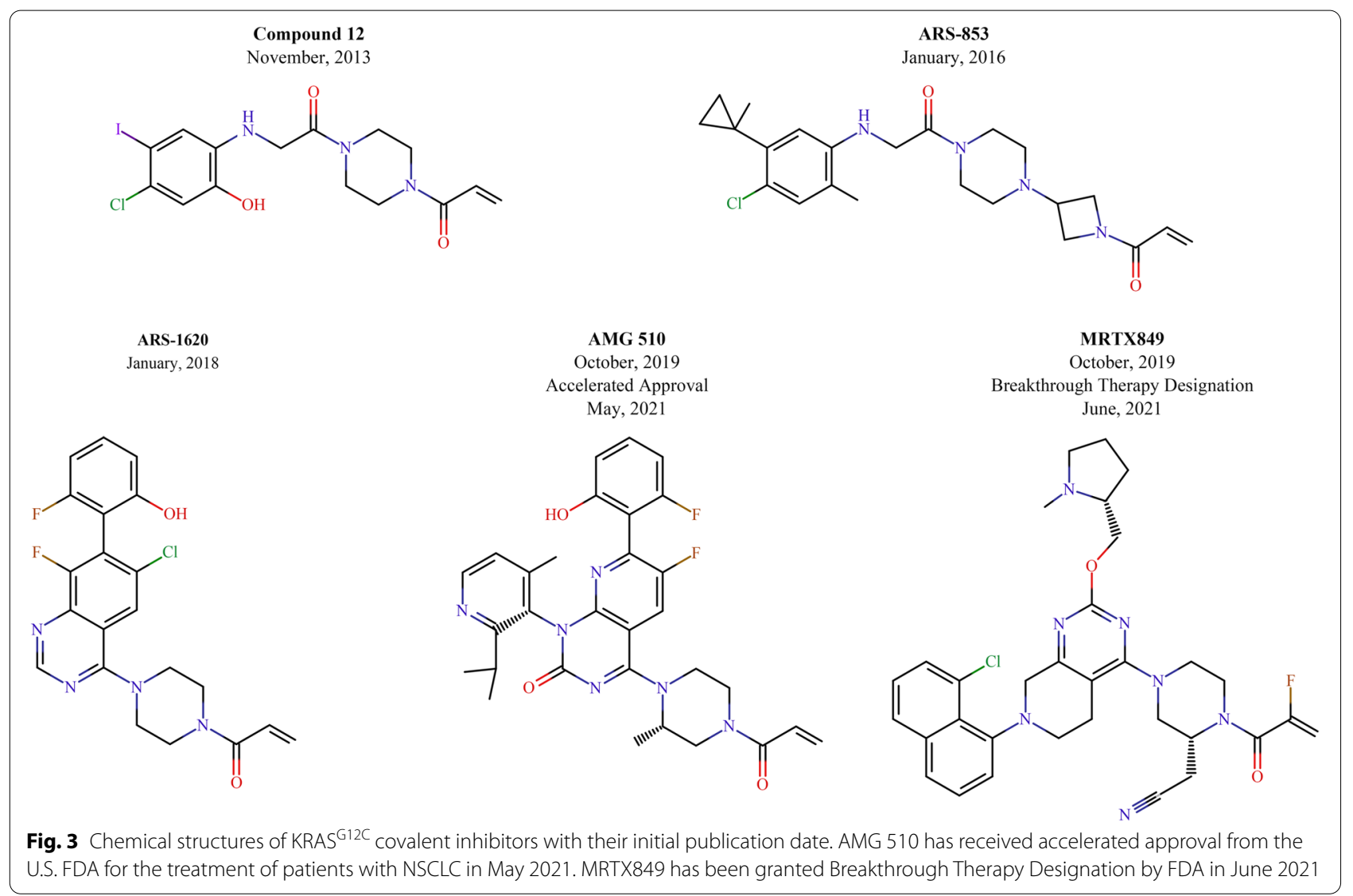

LUMAKRAS $^{\mathrm{TM}}$ (sotorasib), also known as AMG 510, received accelerated approval from the U.S. Food and Drug Administration (FDA) for the treatment of adult patients with $K R A S^{G 12 C}$-mutant locally and metastatic NSCLC who have received at least one prior systemic therapy [69]. The emergence and development of AMG 510 were attributed to the discovery of a surface groove created by an alternative orientation of histidine residue (His95), which could be occupied by aromatic rings and which significantly enhanced its interactions with the KRAS ${ }^{\mathrm{G} 12 \mathrm{C}}$ protein [70]. Therefore, AMG 510, as a His95-binding molecule, is approximately 10 times more effective than ARS-1620, although they are structurally related and overlap [66]. In preclinical models, AMG 510 was able to induce $K R A S^{G 12 C}$-mutant colorectal cancer patient-derived xenograft (CRC PDX) shrinkage. Additionally, in mice bearing CT-26 KRAS ${ }^{G 12 C}$ tumor, AMG 510 also led to tumor regression [66]. In the first human study (NCT03600883), a total of 129 patients with KRAS $S^{G 12 C}$-mutant cancers (59 NSCLC, 42 CRC and 28 other tumors) were enrolled in the study. Among them, NSCLC showed the highest response rate to AMG 510: across all dose levels, $32.2 \%$ (19 patients) had an objective response, $88.1 \%$ (52 patients) had disease control, and the median PFS for all NSCLC patients was 6.3 months. However, the activity in CRC was less promising: 7.1\% (3 patients) had an objective response, $73.8 \%$ (31 patients) had disease control, and the median PFS for all CRC patients was 4.0 months [12]. Notably, no dose-limiting toxicities have been observed with AMG 510, even with extended treatment. In consideration of the poor efficacy of AMG 510 as monotherapy in patients with CRC, combination therapies are being explored. A previous study found that the immune system plays a critical role in the long-term cure induced by AMG 510 in the CT-26 $K R A S^{G 12 C}$ model. Subsequently, AMG 510 treatment was found to induce an inflamed tumor microenvironment and led to increased infiltration and activation of $\mathrm{T}$ cells, which provided a theoretical basis for its combined immunotherapy. Indeed, combination with antiprogrammed cell death 1 (PD-1) therapy enhanced the durability of regression of CT-26 KRAS ${ }^{G 12 C}$ tumors and significantly improved survival [66]. Amodio and colleagues found that $K R A S^{G 12 C}$-mutant CRC cell lines displayed higher basal RTK activation, especially EGFR, than NSCLC cell lines; they then revealed that the reactivation of EGFR reversed the efficacy of AMG 510 in CRC. Therefore, concomitant EGFR inhibition is required to 
acquire a better response after $\mathrm{KRAS}^{\mathrm{G12C}}$ inhibition [71]. Currently, AMG 510 in combination with other inhibitors and chemotherapies is under clinical investigation (NCT04185883; Table 3).

MRTX849 is another potently covalent KRAS ${ }^{\mathrm{G} 12 \mathrm{C}}$ inhibitor. On June 24, 2021, the U.S. FDA granted Breakthrough Therapy Designation to adagrasib (MRTX849) for the potential treatment of patients with $K R A S^{G 12 C_{-}}$ mutant NSCLC following prior systemic therapy [72]. In preclinical models, MRTX849 showed remarkable anti-tumor efficacy exclusively in $K R A S^{G 12 C}$-mutant cell lines and resulted in tumor regression in xenograft models [67]. Further study indicated that the anti-tumor activity of MRTX849 was significantly improved when combined with upstream (EGFR and SHP2) inhibitors and downstream (mTOR and cyclin-dependent kinase 4/6) (CDK4/6) inhibitors [67]. A phase I/II clinical trial of MRTX849 is also ongoing (NCT03785249; Table 2). The updated clinical data of adagrasib were presented at the 2020 EORTC-NCI-AACR International Virtual Conference on Molecular Targets and Therapeutics. As of August 30, 2020, among the evaluable efficacy data in heavily pretreated patients with advanced NSCLC $(n=51)$ treated with MRTX849 as a monotherapy at a $600 \mathrm{mg}$ BID dose, $45.1 \%$ (23 patients) had a confirmed objective response, and $96.1 \%$ (49 patients) had disease control. However, the clinical activity in CRC $(n=18)$ was inferior to that in NSCLC: $16.7 \%$ (3 patients) had an objective response, and $94.4 \%$ (17 patients) had disease control [73]. Therefore, to improve the efficacy of MRTX849 in CRC, trials of its combination of cetuximab (an anti-EGFR antibody) and TNO155 (an SHP2 inhibitor) are underway, but the results have not been published (NCT04793958, NCT04330664; Table 3). Similarly, MRTX849 was well-tolerated across monotherapy and combination trials.

A third KRAS ${ }^{\mathrm{G} 12 \mathrm{C}}$ covalent inhibitor, JNJ-74699157 (ARS-3248), is also being evaluated in a phase I clinical trial (NCT04006301; Table 2). Although the results of the clinical trial have not been published, its predecessor compounds (ARS-853 and ARS-1620) are able to induce tumor regression in PDX models and block downstream signaling to mitogen-activated protein kinase (MAPK) in KRAS ${ }^{G 12 C}$-mutant tumor cell lines [65, 74]. Another KRAS ${ }^{\mathrm{G} 12 \mathrm{C}}$ covalent inhibitor developed by Eli Lilly, LY3499446, has been under clinical investigation (NCT04165031; Table 2) and assessed as a monotherapy and in combination with other inhibitors, including cetuximab, abemaciclib and erlotinib, or with chemotherapy (docetaxel) in advanced solid tumors, including NSCLC and CRC. However, this clinical trial was terminated due to unexpected toxicity.

\section{Targeting the RAS-binding pocket}

Although covalent inhibitors of KRAS ${ }^{\mathrm{G} 12 \mathrm{C}}$ targeting the mutation-specific state are effective, identifying effective treatments for each mutant KRAS protein is cumbersome. Fang, Wang, Fesik, and colleagues identified a series of compounds that could interact with the hydrophobic pocket on the RAS-GDP complex and then block the RAS-SOS interaction, thus inhibiting SOS-mediated nucleotide exchange [75, 76]. In addition, researchers at Kobe University adopted different approaches and made efforts to explore small molecules that could interfere with the interaction between GTP-bound RAS and RAF. Kobe0065, the most promising compound they developed, was proven to bind to RAS-GTP (HRAS and KRAS) and competitively block RAF binding, which inhibited the growth of cancer cells carrying activated $R A S$ oncogenes and tumor xenografts [77].

These compounds function as pan-RAS inhibitors. Therefore, the low specificity of these compounds may pose toxicity problems. Additionally, their low potency in preclinical models may limit their value in clinical applications. Despite the deficiencies of these compounds, they question the theory that KRAS is an "undruggable" target.

\section{Strategies to target KRAS indirectly}

Nucleotide exchange, KRAS processing, and membrane localization are all involved in KRAS activation. Meanwhile, the activation of the KRAS downstream signaling pathways also drives KRAS-mediated oncogenesis. Therefore, interference with any of the above steps can indirectly affect KRAS function.

\section{Inhibitors of the nucleotide exchange cycle}

SOS1 inhibitors In addition to the previously described method of targeting the hydrophobic pocket of the RASGDP complex to inhibit SOS binding, direct inhibition of SOS1 is an effective approach to inhibit GEF activity. Several studies described that a lipophilic pocket of SOS1 adjacent to the RAS-binding site could be occupied by small molecules, which could activate or block the SOSRAS interaction [78, 79]. BAY-293, one of these small molecules, is a selective SOS1 inhibitor that can inhibit the RAS-RAF-MEK-ERK pathway. Additionally, when combined with a KRAS ${ }^{\mathrm{G} 12 \mathrm{C}}$ covalent inhibitor, BAY-293 demonstrated synergistic antiproliferative activity in a $K R A S^{G 12 C}$-mutant cell line, due to its ability to increase the pool of GDP-bound KRAS ${ }^{\mathrm{G} 12 \mathrm{C}}$ [79]. However, BAY293 did not show the expected differential effect on $K R A S$-mutant cancer cell lines versus wild-type KRAS cells. Recently, BI-3406, a more potent and selective SOS1 inhibitor, was developed. BI-3406 is the first orally 
bioavailable inhibitor of the SOS1-KRAS interaction, and it only inhibits SOS1 and not SOS2 [80]. In KRASmutant cancer, whether G12 or G13, BI-3406 decreased the KRAS-GTP level and restricted the proliferation of the majority of tumor cells. Currently, BI 1701963, a BI-3406 analogue, is being evaluated in a phase I clinical trial alone or in combination with trametinib in patients with advanced KRAS-mutant tumors (NCT04111458; Tables 2 and 3).

SHP2 inhibitors SHP2 is a protein tyrosine phosphatase encoded by the gene PTPN11, and its tyrosine phosphorylation contributes to interaction with growth factor receptor-bound protein 2 (GRB2). Thus, it has been speculated that SHP2 acts as a scaffold protein to recruit the GRB2-SOS complex, thereby promoting RAS nucleotide exchange [81, 82]. Therefore, the effect of inhibiting SHP2 is similar to that of SOS1 inhibitors, which block the loading of GTP on wild-type RAS. A previous study demonstrated that SHP2 inhibitors limited the proliferation of KRAS-mutant CRC in vitro and in vivo [83]. More importantly, several studies have indicated that reversing adaptive resistance to MEK inhibitors is a more effective application of SHP2 inhibitors in KRAS-dependent cancers [84-86]. Nevertheless, the tolerability of this combination is a concern. A recent study suggested that the CDK4/6 inhibitor ribociclib could be used as an alternative to the MEK inhibitor trametinib to improve the efficacy of the SHP2 inhibitor TNO155 in KRAS-mutant $\mathrm{CRC}$ and showed better tolerability. Moreover, this study also indicated that TNO155 could improve the efficacy of $\mathrm{KRAS}^{\mathrm{G} 12 \mathrm{C}}$ covalent inhibitors against $K R A S^{\mathrm{G} 12 \mathrm{C}}$ mutant CRC [87]. In addition to tumor intrinsic effects, SHP2 inhibitors also have immunomodulatory effects. In CT-26 and MC38 CRC models, SHP2 inhibitors induce a reduction in protumorigenic M2 macrophages and can improve the efficacy of PD-1 blockade [87, 88]. Currently, there are several SHP2 inhibitors in the early phase of clinical trials. RMC-4630 is in a phase I clinical trial as a single agent (NCT03634982; Table 2) and in a new clinical trial in combination with an ERK inhibitor, LY3214996, for the treatment of patients with metastatic KRAS-mutant cancers (NSCLC, CRC and pancreatic cancer) (NCT04916236; Table 3). A second inhibitor, TNO155, is in a phase Ib/II clinical trial in combination with the KRAS ${ }^{\mathrm{G} 12 \mathrm{C}}$ inhibitor JDQ443 in $K R A S^{G 12 C_{-}}$ mutant cancers, including CRC (NCT04699188; Table 3).

\section{Disruption of KRAS processing and membrane localization}

Localization to the cell membrane is required for KRAS GTP binding and activation, so interference with KRAS membrane association may be a potential approach for targeting KRAS. Post-translational modification of KRAS is the first step of membrane localization, and there are three key enzymes involved in this process: farnesyltransferase (FTase) or geranylgeranyltransferase (GGTase), RAS-converting enzyme (RCE1) and isoprenylcysteine carboxyl methyltransferase (ICMT). Consequently, inhibitors of these enzymes have been developed to attenuate KRAS activity. However, in a preclinical study, $K R A S$-mutant cell lines were found to be less sensitive to the FTase inhibitor tipifarnib than HRAS-mutant cell lines [89]. Similarly, tipifarnib showed disappointing effects in phase II and III clinical trials on patients with advanced CRC $[90,91]$. These results may be due to the functional redundancy between FTase and GGTase. Targeting the downstream RAS processing enzymes, namely, RCE1 and ICMT, is an effective approach to prevent the compensation of FTase inhibitors by GGTase in KRASmutant tumors. Inhibitors of ICMT, such as cysmethynil and UCM-1336, have been developed and have shown a great capability to reduce KRAS activity and impair the growth of KRAS-mutant cell lines [92, 93]. However, the clinical data of ICMT inhibitors in patients with KRASmutant CRC are not yet available.

Post-translationally modified KRAS requires the regulation of prenyl-binding protein phosphodiesterase- $\delta$ (PDE $\delta$ ) to transport and localize to the membrane [94]. Deltarasin, a high-affinity PDE $\delta$-RAS interaction inhibitor, blocks KRAS binding by occupying the farnesyl-binding pocket of PDE $\delta$ and thereby leads to mislocalization of KRAS [95]. In CRC cell lines, deltarasin specifically inhibits the proliferation of cell lines with oncogenic KRAS mutations, and the latest generation of the PDE $\delta$ inhibitor, deltasonamide 2 , shows a more superior suppression effect [96]. However, these inhibitors are quickly released from PDE $\delta$ s induced by Arl2, which hampers their anti-tumor efficacy [97]. Recently, to overcome this limitation, the first-in-class PDE $\delta$ degraders were designed by the proteolysis-targeting chimeric (PROTAC) method from conventional PDE $\delta$ inhibitors to induce PDE $\delta$ degradation. Subsequently, Compound $17 f$, the most promising PDE $\delta$ degrader, shows enhanced anti-tumor activity in the KRAS-mutant CRC cell line and its xenograft model [98].

Notably, the enzymes mentioned above also process other membrane-associated proteins, which may result in off-target effects.

\section{Targeting downstream signaling pathways}

RAF-MEK-ERK inhibitors KRAS activation accelerates dimerization and phosphorylation of its downstream RAF proteins, which induces RAF kinase activity and then contributes to phosphorylation of RAF substrates 
MEK1/2. The phosphorylation cascade continues followed by MEK phosphorylation of the terminal kinase, ERK1/2. Ultimately, activation of ERK1/2 results in activating transcription factors that regulate genes promoting cell growth and preventing cells from undergoing apoptosis [99]. However, the RAF-MEK-ERK cascade is not a linear and unidirectional signaling pathway, as it has multiple inputs and outputs, feed-forward and feedback mechanisms, and multiple scaffold proteins that dynamically regulate signaling and ERK activity [100]. Therefore, only almost complete inhibition of the RAF-MEK-ERK pathway can effectively treat KRAS-mutant tumors.

RAF dimerization mediated by active KRAS, leads to the activation of RAF. LY3009120, an RAF dimer inhibitor, effectively inhibits the activities of the BRAF/CRAF heterodimer and BRAF or CRAF homodimer by occupying both promoters in the dimer, although it can also promote dimerization [101]. In a preclinical setting, LY3009120 displayed an anti-proliferative effect in KRAS-mutant CRC cell lines and inhibited tumor growth in KRAS-mutant xenograft models [102]. Furthermore, its analog, LSN3074753, showed synergistic antitumor activity in KRAS-mutant CRC PDX models when combined with cetuximab [103]. A phase I clinical trial of LY3009120 has been conducted in patients with advanced solid tumors, but the clinical efficacy was extremely limited in CRC patients with the KRAS mutation (NCT02014116; Table 2) [104]. Similarly, another RAF dimer inhibitor, lifirafenib (BGB-283), also showed no responses to patients with $K R A S$-mutant CRC in a phase I clinical trial (NCT02610361; Table 2) [105].

MEK inhibitors as single agents have shown disappointing results in KRAS-mutant tumors, especially in KRASmutant CRC $[106,107]$. This is due to feedback-mediated RAF activation leading to an increase in phosphorylated MEK when KRAS-mutant tumors are treated with MEK inhibitors, which contributes to weak efficacy in these tumors $[108,109]$. Therefore, no MEK inhibitor is clinically approved for the treatment of $K R A S$-mutant tumors. Although both MEK and RAF inhibitor monotherapy are less promising in KRAS-mutant CRC, the combination of these two inhibitors demonstrated synergy in preclinical models of KRAS-mutant CRC cell lines $[110,111]$. Currently, a phase I clinical trial investigating the combination of belvarafenib (HM95573, RAF inhibitor) and cobimetinib (MEK inhibitor) is recruiting patients with locally advanced solid tumors, including CRC (NCT03284502, Table 3). In addition, concomitant blockade of MEK and KRAS exhibits synergistic antitumor effect in KRAS-mutant CRC, which can provide a theoretical basis for the combination of MEK inhibitors and KRAS ${ }^{\mathrm{G} 12 \mathrm{C}}$ covalent inhibitors in treating $K R A S^{G 12 C}$. mutant CRC $[112,113]$.

As ERK is the culminating kinase of this pathway, it has been speculated that inhibition of ERK may provide an effective therapeutic option for KRAS-mutant tumors. However, ERK inhibitors, such as RAF and MEK inhibitors, have shown poor results in clinical trials treating patients with KRAS-mutant tumors, especially those with KRAS-mutant CRC. GDC-0994, an ERK inhibitor, was evaluated as a single agent in a phase I clinical trial. In this trial, 5 patients with $K R A S$-mutant CRC were enrolled and treated with GDC-0994, of which only one achieved stable disease and the remainder had progressive disease (NCT01875705; Table 2) [114]. However, when in combination with a MEK inhibitor, GDC-0994 exhibited enhanced anti-tumor efficacy in KRAS-mutant CRC cell lines [115]. Moreover, GDC-0994 is being evaluated in a phase Ib clinical trial in combination with cobimetinib for the treatment of advanced solid tumors (NCT02457793; Table 3). Other ERK inhibitors, including BVD-523, LY3214996 and MK-8353, are in the early stage of clinical trials either alone or in combination (NCT04566393; Table 2; NCT04916236, NCT02972034; Table 3).

In general, the efficacy of RAF, MEK or ERK inhibitors alone in KRAS-mutant CRC is not satisfactory. Therefore, the focus should be placed more on exploring the use of these inhibitors in combination with other inhibitors of the MAPK pathway or with other inhibitors that we mentioned in this Review, which may bring surprise for the treatment of KRAS-mutant CRC.

PISK-AKT-mTOR inhibitors In addition to the RAFMEK-ERK pathway, PI3K is the second effector pathway that is also activated by KRAS. GTP-bound KRAS stimulates PI3Ks to convert phosphatidylinositol-4,5-bisphosphate to phosphatidylinositol-3,4,5-trisphosphate, which contributes to the recruitment of AKT to the cell membrane where it becomes phosphorylated and then activates mTOR. Therefore, inhibition of this pathway at each node may be an optional approach for the treatment of KRAS-mutant tumors. However, most monotherapies targeting PI3K, AKT, and/or mTOR are ineffective in KRAS-mutant cancer [116].

PI3K pathway inhibitors are more suitable as an option in combination therapy for KRAS-mutant cancers, because there are overlapping feedback mechanisms between the MAPK and PI3K pathways, meaning that inhibition of one pathway can result in the compensatory activation of the other $[111,117,118]$. Therefore, the combination 
of MAPK and PI3K inhibitors may be a compelling regimen for the treatment of $K R A S$-mutant cancers. In KRAS-mutant CRC cell lines, PI3K pathway inhibitors overcome resistance to MEK inhibitors and significantly inhibit cell proliferation. Moreover, this robust synergistic activity has also been observed in mouse models [117, 119]. However, in clinical trials, these combined treatment strategies appear to be ineffective in patients with KRAS-mutant CRC, which may be the result of dose limitation due to toxicity [120-122].

Furthermore, upregulation of the PI3K pathway can also occur through activating mutations in PIK3CA, which encodes catalytic p110 $\alpha$ kinase activity. This mutation can coexist with KRAS mutations, which suggests that inhibitors targeting KRAS are sufficient to inhibit the MAPK pathway rather than the PI3K pathway [123, 124]. Therefore, the combination of PI3K inhibitors and other inhibitors that we mentioned in this Review, especially KRAS $^{\mathrm{G} 12 \mathrm{C}}$ covalent inhibitors, may be a potential treatment strategy for KRAS-mutant CRC.

\section{Emerging therapeutics}

\section{Immune checkpoint inhibitors}

Blockade of the immune checkpoint axis, such as targeting PD-L1 (programmed cell death ligand 1) or its receptor PD-1, has induced striking regressions in various malignancies. Several antibodies targeting immune checkpoint proteins have been approved by FDA and achieved a favorable clinical effect in many cancers. However, most patients with CRC, except for those with high levels of microsatellite instability (MSI) or deficient mismatch repair (dMMR), cannot therapeutically benefit from immunotherapies because they have low immunogenicity [125-127]. Furthermore, recent studies have shown that KRAS-mutant CRC have significantly reduced infiltration of naïve $B$ cells, macrophage $M 1$, activated CD4 T cells, cytotoxic cells and neutrophils, and obviously increased regulatory $\mathrm{T}$ cells compared to patients with KRAS wild-type CRC $[128,129]$. Besides, multiple immune-related pathways are down-regulated in KRAS-mutant CRC, such as the interferon- $\gamma$ (IFN- $\gamma$ ) pathway [129]. Therefore, these results may indicate that KRAS-mutant CRC harbor a more immunosuppressive microenvironment, which significantly limits the use of immune checkpoint inhibitors as monotherapy in this group of CRC patients. However, recent studies have found that treatment of KRAS ${ }^{\mathrm{G} 12 \mathrm{C}}$ allele-specific inhibitors or SHP2 inhibitors, or MEK inhibitors could activate anti-tumor immune cells and thereby relieve immunosuppressive status, which improves the response of $K R A S$-mutant CRC to immune checkpoint inhibitors in preclinical models $[66,87,88,130]$. These results suggest that the combination of immune checkpoint inhibitors with these KRAS-targeted therapies is promising for the treatment of $K R A S$-mutant CRC, but the clinical efficacy of these combination therapies needs to validate in subsequent clinical trials.

\section{Adoptive cell therapy}

Neoantigens derived from KRAS variants are regarded as "nonself" by immune system and can be recognized by antigen-specific T-cells, which make them become a potential target for immunotherapy. In a patient with metastatic $K R A S^{G 12 D}$-mutant CRC, CD8+ T cells with human leukocyte antigen (HLA)-C*08:02-restricted T-cell receptors (TCRs) were found to specifically recognize mutant KRAS ${ }^{\mathrm{G} 12 \mathrm{D}}$. After expanding ex vivo, tumorinfiltration lymphocytes (TILs) containing approximately $75 \% \mathrm{KRAS}^{\mathrm{G} 12 \mathrm{D}}$-specific CD8+ $\mathrm{T}$ cells were infused into patients. Subsequently, all seven metastatic lung lesions were observed to regress and the patient had a partial response (PR) lasting 9 months [131]. Similarly, in another study, KRAS ${ }^{\mathrm{G} 12 \mathrm{~V}}$-mutant-specific TCRs in CD4+ T cells were identified from patients with NSCLC [132]. Moreover, a previous study immunized HLA$\mathrm{A}^{* 11}$ 1:01 transgenic mice with mutant $\mathrm{KRAS}^{\mathrm{G} 12 \mathrm{D}}$ or KRAS $^{\mathrm{G} 12 \mathrm{~V}}$ peptides to generate $\mathrm{T}$ cells specific to these mutations. Subsequently, researchers identified the TCRs from these $T$ cells and cloned them, and finally retrovirally transduced them into peripheral blood lymphocytes to cultivate $\mathrm{KRAS}^{\mathrm{G} 12 \mathrm{D}}$ or $\mathrm{KRAS}^{\mathrm{G} 12 \mathrm{~V}}$-reactive $\mathrm{T}$ cells [133]. These engineering $\mathrm{T}$ cells were proved to inhibit KRAS ${ }^{\mathrm{G} 12 \mathrm{D}}$-mutant pancreatic tumor growth in a xenograft model [133]. Currently, this approach is using in two clinical trials for the treatment of patients with advanced $K R A S^{G 12 D}$ or $K R A S^{G 12 V}$-mutant solid tumors, including CRC (NCT03745326, NCT03190941; Table 2).

\section{Anti-RAS vaccines}

Another emerging therapeutic is using vaccines to neutralize KRAS protein. The GI- 4000 series, a kind of heatkilled recombinant Saccharomyces cerevisiae-derived vaccine expressing mutant RAS protein, was found to induce remission of tumors in preclinical models [134]. Furthermore, GI-4000 showed a favorable safety and immunological profile in the majority of patients with CRC in a phase I clinical trial [135]. Another approach using Targovax's RAS peptides in combination with granulocyte-macrophage colony-stimulating factor (GM-CSF) is also able to elicit a $\mathrm{T}$ cell anti-tumor immune response to mutant RAS peptides [136]. TG02, Targovax's second generation vaccine, has been studied in a phase Ib clinical trial in CRC as a monotherapy or in combination with the immune checkpoint inhibitor 
pembrolizumab, but the results have not been reported (NCT02933944; Tables 2 and 3). Currently, an mRNA vaccine that uses an mRNA to encode novel epitopes for common KRAS mutations has been developed and is able to trigger a $\mathrm{T}$ cell response against these mutant KRAS neo-epitopes. Meanwhile, the safety and tolerability of one such mRNA vaccine, mRNA-5671, is being evaluated in a phase I clinical trial as a monotherapy or in combination with pembrolizumab in participants with KRAS-mutant tumors (NSCLC, CRC, and pancreatic adenocarcinoma) (NCT03948763; Tables 2 and 3).

\section{Future directions and conclusions}

$K R A S$ is frequently mutated in CRC, and it is involved in the occurrence, progression, treatment resistance and recurrence of CRC. Considerable evidence demonstrates that KRAS mutations indicate a dismal prognosis for patients with CRC. The development of point mutation detection techniques has promoted the analysis of biopsy specimens and enables the analysis of plasma- and serum-containing ctDNA, allowing for early and accurate detection of KRAS mutations in CRC patients. Due to the presence of mutated KRAS, this group of CRC patients requires more precise and personalized treatment. However, historical KRAS-targeted therapies did not achieve satisfactory efficacy in patients with KRAS-mutant CRC. Recently, the development of KRAS ${ }^{\mathrm{G} 12 \mathrm{C}}$ allele-specific inhibitors has relighted the hope for KRAS-targeted therapies and simultaneously reveals areas for further exploration in the future.

First, more types of KRAS allele-specific inhibitors should be developed. The emergence of KRAS ${ }^{\mathrm{G} 12 \mathrm{C}}$ allelespecific inhibitors breaks the traditional view that KRAS is undruggable, which changes the outlook of treatment for KRAS-driven tumors. However, in CRC, KRAS ${ }^{\mathrm{G} 12 \mathrm{D}}$ and KRAS ${ }^{\mathrm{G} 12 \mathrm{~V}}$ are the most common mutation subtypes and are associated with the largest patient populations (Fig. 2a). Therefore, inhibitors specific to these alleles need to be further developed. Ultimately, specific inhibitors will be required for all mutant KRAS alleles to provide more personalized treatment for patients. Notably, $\mathrm{KRAS}^{\mathrm{G} 12 \mathrm{C}}$ is unique among KRAS oncoproteins due to its high intrinsic GTP hydrolysis rate, which leaves more KRAS in an inactive state to facilitate KRAS ${ }^{\mathrm{G} 12 \mathrm{C}}$ allelespecific inhibitor binding. Therefore, solving the problem of the low GTP hydrolysis rate of other KRAS allele mutations is a challenge for satisfactory efficacy of other KRAS allele-specific inhibitors.

Second, the underlying resistance mechanisms of the drug treating KRAS-mutant CRC need to be elucidated. Several studies have indicated that KRAS-mutant CRC has an inferior response to most KRAS-targeted therapies, including KRAS ${ }^{\mathrm{G} 12 \mathrm{C}}$ allele-specific inhibitors, compared to NSCLC. Is the KRAS mutation in CRC not a driver mutation? Does the tumor have mutations in other KRAS alleles due to the heterogeneity of CRC? Actually, the paradigms of precision medicine in CRC have shifted from 'one-gene, one-drug' to 'multi-gene, multi-drug' and further to 'multi-molecular, multi-drug'. Previously, an international consortium has merged six independent transcriptomic-based subtype systems that have significant interconnectivity into four consensus molecular subtypes (CMSs) with distinct characteristics: CMS1 (MSI immune); CMS2 (canonical); CMS3 (metabolic); and finally CMS4 (mesenchymal) [137]. Among these subtypes, KRAS mutations are enriched in CMS3 (68\%), but they are also presented in other three subtypes with different proportions (23\% in CMS1, 28\% in CMS2, and $38 \%$ in CMS4), which indicates that KRAS-mutant CRC is still highly heterogeneous, and it is not advisable to rely solely on this single gene alternation to guide the treatment of CRC patients. Therefore, it is essential to integrate multi-omics data (genome, transcriptome, epigenome, metabolome and immunome) to comprehensively understand the molecular network and to refine the molecular stratification of KRAS-mutant CRC, which may help to develop combination therapies that are more suitable for KRAS-mutant CRC.

Finally, toxicity and safety should be taken into account when designing combination strategies. Historically, the efficacy of combination treatment is largely limited by toxicity, such as the combination of MEK and PI3K inhibitors. $\mathrm{KRAS}^{\mathrm{G} 12 \mathrm{C}}$ allele-specific inhibitors are reported to lack dose-limiting toxicities in clinical trials, which allow them to replace some of the more toxic inhibitors in combination regimens, thereby making them more tolerable to patients.

In summary, KRAS plays a critical role in the prognosis, diagnosis and treatment of CRC. The success of KRAS ${ }^{\mathrm{G} 12 \mathrm{C}}$ allele-specific inhibitors has pushed research on targeting KRAS to a new level, which may lead to the development of more promising KRAS-targeted approaches and provide the possibility for conquering KRAS mutations in CRC.

\section{Abbreviations}

CRC: Colorectal cancer; KRAS: Kirsten rat sarcoma; RTK: Receptor tyrosine kinase; EGFR: Epidermal growth factor receptor; GTP: Guanosine triphosphate; GDP: Guanosine diphosphate; GTPase: Guanosine triphosphatase; GEFs: Guanine exchange factors; SOS: Son of sevenless; GAPs: GTPase activating proteins; RAF: Rapidly accelerated fibrosarcoma; MEK: Mitogen-activated protein kinase kinase; ERK: Extracellular signal-regulated kinase; PI3K: Phosphatidylinositol 3-kinase; AKT: Protein kinase B; mTOR: Mechanistic target of rapamycin; OS: Overall survival; FOLFOX: 5-fluorouracil, leucovorin, and oxaliplatin; PFS: Progression-free survival; FFPE: Formalin-fixed paraffin-embedded; FNA: Fineneedle aspiration; PCR: Polymerase chain reaction; ARMS: Amplification refractory mutation system; NGS: Next generation sequencing; ctDNA: Circulating tumor DNA; cfDNA: Cell-free DNA; NSCLC: Non-small-cell lung cancer; FDA: Food and Drug Administration; PDX: Patient-derived xenografts; OR: Objective 
response; CDK4/6: Cyclin-dependent kinase 4/6; MAPK: Mitogen-activated protein kinase; GM-CSF: Granulocyte-macrophage colony-stimulating factor; GRB2: Growth factor receptor-bound protein 2; FTase: Farnesyltransferase; GGTase: Geranylgeranyltransferase; RCE1: RAS-converting enzyme; ICMT: Isoprenylcysteine carboxyl methyltransferase; PDES: Prenyl-binding protein phosphodiesterase- $\delta ;$ PD-1: Programmed cell death 1; PD-L1: Programmed cell death ligand 1; MSI: Microsatellite instability; dMMR: Deficient mismatch repair; IFN- $\gamma$ : Interferon- $\gamma$; TCR: T-cell receptor; TILs: Tumor-infiltration lymphocytes; PR: Partial response; CMSs: Consensus molecular subtypes.

\section{Supplementary Information}

The online version contains supplementary material available at https://doi. org/10.1186/s12943-021-01441-4.

Additional file 1: Table S1. Characteristics of KRAS targeting dugs.

\section{Acknowledgements}

Not applicable.

\section{Authors' contributions}

FB contributed to the direction and guidance of this review; GZ and LP drafted the manuscript and prepared the figures; HX and QT made the table and revised the manuscript; FB given the final approval of the version to be published. All authors read and approved the final manuscript.

\section{Funding}

This study was supported by grants from Science and Technology Department of Sichuan Province (No. 2019YJ0056), the National Natural Science Foundation of China (No. 82073059), the National Natural Science Foundation of China (No. 81872020), 1.3.5 Project for Disciplines of Excellence, West China Hospital, Sichuan University (No. ZYGD18005), the National Natural Science Foundation of China (No. 81621003), and the National Natural Science Foundation of China (No. 82073314).

\section{Availability of data and materials}

Not applicable.

\section{Declarations}

\section{Ethics approval and consent to participate}

Not applicable.

\section{Consent for publication}

Not applicable.

\section{Competing interests}

The authors declare that they have no competing interests.

\section{Author details}

1 Department of Abdominal Oncology, Cancer Center and Laboratory of Molecular Targeted Therapy in Oncology, West China Hospital, Sichuan University, No.37 guoxue lane, Chengdu 610041, Sichuan Province, China. ${ }^{2}$ The State Key Laboratory of Biotherapy, West China Hospital, Sichuan University, Chengdu 610041, Sichuan Province, China.

Received: 22 July 2021 Accepted: 4 October 2021

Published online: 06 November 2021

\section{References}

1. Bray F, Ferlay J, Soerjomataram I, Siegel RL, Torre LA, Jemal A. Global cancer statistics 2018: GLOBOCAN estimates of incidence and mortality worldwide for 36 cancers in 185 countries. CA Cancer J Clin. 2018;68:394-424.

2. Kennedy RD, Bylesjo M, Kerr P, Davison T, Black JM, Kay EW, et al. Development and independent validation of a prognostic assay for stage
II colon cancer using formalin-fixed paraffin-embedded tissue. J Clin Oncol. 2011;29:4620-6.

3. Fearon ER, Vogelstein B. A genetic model for colorectal tumorigenesis. Cell. 1990;61:759-67.

4. Sagaert $X$, Vanstapel A, Verbeek S. Tumor heterogeneity in colorectal Cancer: what Do we know so far? Pathobiology. 2018;85:72-84.

5. Sasaki N, Clevers H. Studying cellular heterogeneity and drug sensitivity in colorectal cancer using organoid technology. Curr Opin Genet Dev. 2018;52:117-22.

6. Martini G, Dienstmann R, Ros J, Baraibar I, Cuadra-Urteaga JL, Salva F, et al. Molecular subtypes and the evolution of treatment management in metastatic colorectal cancer. Ther Adv Med Oncol. 2020;12:1758835920936089.

7. Dienstmann R, Connor K, Byrne AT. Precision therapy in RAS mutant colorectal Cancer. Gastroenterology. 2020;158:806-11.

8. Roth AD, Tejpar S, Delorenzi M, Yan P, Fiocca R, Klingbiel D, et al. Prognostic role of KRAS and BRAF in stage II and III resected colon cancer: results of the translational study on the PETACC-3, EORTC 40993, SAKK 60-00 trial. J Clin Oncol. 2010;28:466-74.

9. Dienstmann R, Mason MJ, Sinicrope FA, Phipps Al, Tejpar S, Nesbakken A, et al. Prediction of overall survival in stage II and III colon cancer beyond TNM system: a retrospective, pooled biomarker study. Ann Oncol. 2017;28:1023-31.

10. Karapetis CS, Khambata-Ford S, Jonker DJ, O'Callaghan CJ, Tu D, Tebbutt $\mathrm{NC}$, et al. K-ras mutations and benefit from cetuximab in advanced colorectal cancer. N Engl J Med. 2008;359:1757-65.

11. Amado RG, Wolf M, Peeters M, Van Cutsem E, Siena S, Freeman DJ, et al. Wild-type KRAS is required for panitumumab efficacy in patients with metastatic colorectal cancer. J Clin Oncol. 2008;26:1626-34

12. Hong DS, Fakih MG, Strickler JH, Desai J, Durm GA, Shapiro Gl, et al. KRAS(G12C) inhibition with Sotorasib in advanced solid tumors. N Engl J Med. 2020;383:1207-17.

13. Chen Z, Otto JC, Bergo MO, Young SG, Casey PJ. The C-terminal polylysine region and methylation of K-Ras are critical for the interaction between K-Ras and microtubules. J Biol Chem. 2000;275:41251-7.

14. Pells S, Divjak M, Romanowski P, Impey H, Hawkins NJ, Clarke AR, et al. Developmentally-regulated expression of murine K-ras isoforms. Oncogene. 1997;15:1781-6.

15. Tsai FD, Lopes MS, Zhou M, Court H, Ponce O, Fiordalisi JJ, et al. $\mathrm{K}$-Ras4A splice variant is widely expressed in cancer and uses a hybrid membrane-targeting motif. Proc Natl Acad Sci U S A. 2015;112:779-84.

16. Chen W-C, To MD, Westcott PMK, Delrosario R, Kim I-J, Philips M, Tran Q, Bayani N, Balmain A. Regulation of KRAS4A/B splicing in cancer stem cells by the RBM39 splicing complex. Preprint at bioRxiv. 2019. https:// doi.org/10.1101/646125.

17. Bourne HR, Sanders DA, McCormick F. The GTPase superfamily: conserved structure and molecular mechanism. Nature. 1991;349:117-27.

18. Hancock JF, Parton RG. Ras plasma membrane signalling platforms. Biochem J. 2005;389:1-11.

19. Vögler O, Barceló JM, Ribas C, Escribá PV. Membrane interactions of $\mathrm{G}$ proteins and other related proteins. Biochim Biophys Acta. 2008;1778:1640-52.

20. Simanshu DK, Nissley DV, McCormick F. RAS proteins and their regulators in human disease. Cell. 2017;170:17-33.

21. Cherfils J, Zeghouf M. Regulation of small GTPases by GEFs, GAPs, and GDls. Physiol Rev. 2013;93:269-309.

22. Li Z, Chen Y, Wang D, Wang G, He L, Suo J. Detection of KRAS mutations and their associations with clinicopathological features and survival in Chinese colorectal cancer patients. J Int Med Res. 2012;40:1589-98.

23. Cercek A, Braghiroli MI, Chou JF, Hechtman JF, Kemeny N, Saltz L, et al. Clinical features and outcomes of patients with colorectal cancers harboring NRAS mutations. Clin Cancer Res. 2017;23:4753-60.

24. Haigis KM. KRAS alleles: the devil is in the detail. Trends Cancer. 2017;3:686-97.

25. Hunter JC, Manandhar A, Carrasco MA, Gurbani D, Gondi S, Westover KD. Biochemical and structural analysis of common Cancer-associated KRAS mutations. Mol Cancer Res. 2015;13:1325-35.

26. Smith MJ, Neel BG, Ikura M. NMR-based functional profiling of RASopathies and oncogenic RAS mutations. Proc Natl Acad Sci U S A. 2013;110:4574-9 
27. Imamura Y, Morikawa T, Liao X, Lochhead P, Kuchiba A, Yamauchi $M$, et al. Specific mutations in KRAS codons 12 and 13 , and patient prognosis in 1075 BRAF wild-type colorectal cancers. Clin Cancer Res. 2012;18:4753-63.

28. Jones RP, Sutton PA, Evans JP, Clifford R, McAvoy A, Lewis J, et al. Specific mutations in KRAS codon 12 are associated with worse overall survival in patients with advanced and recurrent colorectal cancer. Br J Cancer. 2017;116:923-9.

29. Modest DP, Ricard I, Heinemann V, Hegewisch-Becker S, Schmiegel W, Porschen R, et al. Outcome according to KRAS-, NRAS- and BRAFmutation as well as KRAS mutation variants: pooled analysis of five randomized trials in metastatic colorectal cancer by the AIO colorectal cancer study group. Ann Oncol. 2016;27:1746-53.

30. Camaj P, Primo S, Wang Y, Heinemann V, Zhao Y, Laubender RP, et al. KRAS exon 2 mutations influence activity of regorafenib in an SW48-based disease model of colorectal cancer. Future Oncol. 2015;11:1919-29.

31. Zocche DM, Ramirez C, Fontao FM, Costa LD, Redal MA. Global impact of KRAS mutation patterns in FOLFOX treated metastatic colorectal cancer. Front Genet. 2015:6:116.

32. Jonker DJ, O'Callaghan CJ, Karapetis CS, Zalcberg JR, Tu D, Au HJ, et al. Cetuximab for the treatment of colorectal cancer. N Engl J Med. 2007;357:2040-8

33. Loupakis F, Ruzzo A, Cremolini C, Vincenzi B, Salvatore L, Santini D, et al. KRAS codon 61, 146 and BRAF mutations predict resistance to cetuximab plus irinotecan in KRAS codon 12 and 13 wild-type metastatic colorectal cancer. Br J Cancer. 2009;101:715-21.

34. Douillard JY, Oliner KS, Siena S, Tabernero J, Burkes R, Barugel M, et al. Panitumumab-FOLFOX4 treatment and RAS mutations in colorectal cancer. N Engl J Med. 2013;369:1023-34.

35. Allegra CJ, Rumble RB, Hamilton SR, Mangu PB, Roach N, Hantel A, et al. Extended RAS gene mutation testing in metastatic colorectal carcinoma to predict response to anti-epidermal growth factor receptor monoclonal antibody therapy: American Society of Clinical Oncology provisional clinical opinion update 2015. J Clin Oncol. 2016;34:179-85.

36. De Roock W, Jonker DJ, Di Nicolantonio F, Sartore-Bianchi A, Tu D, Siena S, et al. Association of KRAS p.G13D mutation with outcome in patients with chemotherapy-refractory metastatic colorectal cancer treated with cetuximab. JAMA. 2010;304:1812-20.

37. Tejpar S, Celik I, Schlichting M, Sartorius U, Bokemeyer C, Van Cutsem E. Association of KRAS G13D tumor mutations with outcome in patients with metastatic colorectal cancer treated with first-line chemotherapy with or without cetuximab. J Clin Oncol. 2012;30:3570-7.

38. De Roock W, Claes B, Bernasconi D, De Schutter J, Biesmans B, Fountzilas $G$, et al. Effects of KRAS, BRAF, NRAS, and PIK3CA mutations on the efficacy of cetuximab plus chemotherapy in chemotherapy-refractory metastatic colorectal cancer: a retrospective consortium analysis. Lancet Oncol. 2010;11:753-62.

39. Bozzetti C, Negri FV, Azzoni C, Naldi N, Nizzoli R, Bortesi B, et al. Epidermal growth factor receptor and Kras gene expression: reliability of mutational analysis on cytological samples. Diagn Cytopathol. 2013:41:595-8.

40. Mohamed Suhaimi NA, Foong YM, Lee DY, Phyo WM, Cima I, Lee EX, et al. Non-invasive sensitive detection of KRAS and BRAF mutation in circulating tumor cells of colorectal cancer patients. Mol Oncol. 2015;9:850-60.

41. Isler JA, Vesterqvist OE, Burczynski ME. Analytical validation of genotyping assays in the biomarker laboratory. Pharmacogenomics. 2007;8:353-68.

42. Linardou H, Briasoulis E, Dahabreh IJ, Mountzios G, Papadimitriou C, Papadopoulos S, et al. All about KRAS for clinical oncology practice: gene profile, clinical implications and laboratory recommendations for somatic mutational testing in colorectal cancer. Cancer Treat Rev. 2011;37:221-33.

43. Cross J. DxS Ltd. Pharmacogenomics. 2008;9:463-7.

44. Tol J, Koopman M, Cats A, Rodenburg CJ, Creemers GJ, Schrama JG, et al. Chemotherapy, bevacizumab, and cetuximab in metastatic colorectal cancer. N Engl J Med. 2009;360:563-72.

45. Fariña Sarasqueta A, Moerland E, de Bruyne $H$, de Graaf $H$, Vrancken T, van Lijnschoten G, et al. SNaPshot and StripAssay as valuable alternatives to direct sequencing for KRAS mutation detection in colon cancer routine diagnostics. J Mol Diagn. 2011;13:199-205.

46. Gonzalez de Castro D, Angulo B, Gomez B, Mair D, Martinez R, SuarezGauthier A, et al. A comparison of three methods for detecting KRAS mutations in formalin-fixed colorectal cancer specimens. $\mathrm{Br} J$ Cancer. 2012;107:345-51.

47. Harlé A, Filhine-Tresarrieu P, Husson M, Boidot R, Rouyer M, Dubois C, et al. Rare RAS mutations in metastatic colorectal Cancer detected during routine RAS genotyping using next generation sequencing. Target Oncol. 2016;11:363-70.

48. Dong L, Wang S, Fu B, Wang J. Evaluation of droplet digital PCR and next generation sequencing for characterizing DNA reference material for KRAS mutation detection. Sci Rep. 2018;8:9650.

49. Taly V, Pekin D, Benhaim L, Kotsopoulos SK, Le Corre D, Li X, et al. Multiplex picodroplet digital PCR to detect KRAS mutations in circulating DNA from the plasma of colorectal cancer patients. Clin Chem. 2013;59:1722-31.

50. García-Foncillas J, Alba E, Aranda E, Díaz-Rubio E, López-López R, Tabernero J, et al. Incorporating BEAMing technology as a liquid biopsy into clinical practice for the management of colorectal cancer patients: an expert taskforce review. Ann Oncol. 2017;28:2943-9.

51. Timar J, Kashofer K. Molecular epidemiology and diagnostics of KRAS mutations in human cancer. Cancer Metastasis Rev. 2020;39:1029-38.

52. Thierry AR, Mouliere F, El Messaoudi S, Mollevi C, Lopez-Crapez E, Rolet $F$, et al. Clinical validation of the detection of KRAS and BRAF mutations from circulating tumor DNA. Nat Med. 2014;20:430-5.

53. Van Cutsem E, Köhne CH, Láng I, Folprecht G, Nowacki MP, Cascinu S, et al. Cetuximab plus irinotecan, fluorouracil, and leucovorin as first-line treatment for metastatic colorectal cancer: updated analysis of overall survival according to tumor KRAS and BRAF mutation status. J Clin Oncol. 2011:29:2011-9.

54. Normanno N, Cervantes A, Ciardiello F, De Luca A, Pinto C. The liquid biopsy in the management of colorectal cancer patients: current applications and future scenarios. Cancer Treat Rev. 2018;70:1-8.

55. Diehl F, Schmidt K, Choti MA, Romans K, Goodman S, Li M, et al. Circulating mutant DNA to assess tumor dynamics. Nat Med. 2008;14:985-90.

56. Garcia J, Forestier J, Dusserre E, Wozny AS, Geiguer F, Merle P, et al. Cross-platform comparison for the detection of RAS mutations in cfDNA (ddPCR biorad detection assay, BEAMing assay, and NGS strategy). Oncotarget. 2018;9:21122-31.

57. Tabernero J, Lenz HJ, Siena S, Sobrero A, Falcone A, Ychou M, et al. Analysis of circulating DNA and protein biomarkers to predict the clinical activity of regorafenib and assess prognosis in patients with metastatic colorectal cancer: a retrospective, exploratory analysis of the CORRECT trial. Lancet Oncol. 2015;16:937-48.

58. Papke B, Der CJ. Drugging RAS: know the enemy. Science. 2017;355:1158-63.

59. Ostrem JM, Shokat KM. Direct small-molecule inhibitors of KRAS: from structural insights to mechanism-based design. Nat Rev Drug Discov. 2016;15:771-85.

60. Passiglia F, Malapelle U, Del Re M, Righi L, Pagni F, Furlan D, et al. KRAS inhibition in non-small cell lung cancer: past failures, new findings and upcoming challenges. Eur J Cancer. 2020;137:57-68.

61. Nagasaka M, Li Y, Sukari A, Ou SI, Al-Hallak MN, Azmi AS. KRAS G12C game of thrones, which direct KRAS inhibitor will claim the iron throne? Cancer Treat Rev. 2020;84:101974.

62. Serna-Blasco R, Sanz-Álvarez M, Aguilera Ó, García-Foncillas J. Targeting the RAS-dependent chemoresistance: the Warburg connection. Semin Cancer Biol. 2019;54:80-90.

63. Ostrem JM, Peters U, Sos ML, Wells JA, Shokat KM. K-Ras (G12C) inhibitors allosterically control GTP affinity and effector interactions. Nature. 2013;503:548-51.

64. Patricelli MP, Janes MR, Li LS, Hansen R, Peters U, Kessler LV, et al. Selective inhibition of oncogenic KRAS output with small molecules targeting the inactive state. Cancer Discov. 2016;6:316-29.

65. Janes MR, Zhang J, Li LS, Hansen R, Peters U, Guo X, et al. Targeting KRAS Mutant Cancers with a Covalent G12C-Specific Inhibitor. Cell. 2018;172:578-89 e517. 
66. Canon J, Rex K, Saiki AY, Mohr C, Cooke K, Bagal D, et al. The clinical KRAS(G12C) inhibitor AMG 510 drives anti-tumour immunity. Nature. 2019;575:217-23.

67. Hallin J, Engstrom LD, Hargis L, Calinisan A, Aranda R, Briere DM, et al. The KRAS(G12C) inhibitor MRTX849 provides insight toward therapeutic susceptibility of KRAS-mutant cancers in mouse models and patients. Cancer Discov. 2020;10:54-71.

68. Christensen JG, Olson P, Briere T, Wiel C, Bergo MO. Targeting Kras(g12C) -mutant cancer with a mutation-specific inhibitor. J Intern Med. 2020;288:183-91.

69. FDA Approves LUMAKRAS ${ }^{\mathrm{TM}}$ (Sotorasib), The First And Only Targeted Treatment For Patients With KRAS G12C-Mutated Locally Advanced Or Metastatic Non-Small Cell Lung Cancer. 2021 https://www.prnewswire. $\mathrm{com} /$ news-releases/fda-approves-lumakras-sotorasib-the-first-andonly-targeted-treatment-for-patients-with-kras-g12c-mutated-local ly-advanced-or-metastatic-non-small-cell-lung-cancer-301301808.html.

70. Gentile DR, Rathinaswamy MK, Jenkins ML, Moss SM, Siempelkamp BD, Renslo AR, et al. Ras Binder Induces a Modified Switch-Il Pocket in GTP and GDP States. Cell Chem Biol. 2017;24:1455-66 e1414.

71. Amodio V, Yaeger R, Arcella P, Cancelliere C, Lamba S, Lorenzato A, et al. EGFR blockade reverts resistance to KRAS(G12C) inhibition in colorectal Cancer. Cancer Discov. 2020;10:1129-39.

72. Mirati Therapeutics'Adagrasib Receives Breakthrough Therapy Designation from U.S. Food and Drug Administration for Patients with Advanced Non-Small Cell Lung Cancer Harboring the KRAS ${ }^{\mathrm{G} 12 \mathrm{C}}$ Mutation. 2021. https://ir.mirati.com/press-releases/press-release-detai Is/2021/Mirati-Therapeutics-Adagrasib-Receives-Breakthrough-Thera py-Designation-from-U.S.-Food-and-Drug-Administration-for-Patie nts-with-Advanced-Non-Small-Cell-Lung-Cancer-Harboring-the-KRASG12C-Mutation/default.aspx.

73. Mirati Therapeutics Reports Investigational Adagrasib (MRTX849) Preliminary Data Demonstrating Tolerability and Durable Anti-Tumor Activity as well as Initial MRTX1133 Preclinical Data. 2020. https://ir. mirati.com/press-releases/press-release-details/2020/Mirati-Thera peutics-Reports-Investigational-Adagrasib-MRTX849-Preliminary-DataDemonstrating-Tolerability-and-Durable-Anti-Tumor-Activity-as-wellas-Initial-MRTX1133-Preclinical-Data/default.aspx.

74. Lito P, Solomon M, Li LS, Hansen R, Rosen N. Allele-specific inhibitors inactivate mutant KRAS G12C by a trapping mechanism. Science. 2016:351:604-8

75. Maurer T, Garrenton LS, Oh A, Pitts K, Anderson DJ, Skelton NJ, et al. Small-molecule ligands bind to a distinct pocket in Ras and inhibit SOS-mediated nucleotide exchange activity. Proc Natl Acad Sci U S A. 2012;109:5299-304.

76. Sun Q, Burke JP, Phan J, Burns MC, Olejniczak ET, Waterson AG, et al. Discovery of small molecules that bind to K-Ras and inhibit Sos-mediated activation. Angew Chem Int Ed Eng. 2012;51:6140-3.

77. Shima F, Yoshikawa Y, Ye M, Araki M, Matsumoto S, Liao J, et al. In silico discovery of small-molecule Ras inhibitors that display antitumor activity by blocking the Ras-effector interaction. Proc Natl Acad Sci U S A. 2013;110:8182-7.

78. Burns MC, Sun Q, Daniels RN, Camper D, Kennedy JP, Phan J, et al. Approach for targeting Ras with small molecules that activate SOS-mediated nucleotide exchange. Proc Natl Acad Sci U S A. 2014;111:3401-6.

79. Hillig RC, Sautier B, Schroeder J, Moosmayer D, Hilpmann A, Stegmann $C M$, et al. Discovery of potent SOS1 inhibitors that block RAS activation via disruption of the RAS-SOS1 interaction. Proc Natl Acad Sci U S A. 2019;116:2551-60.

80. Hofmann MH, Gmachl M, Ramharter J, Savarese F, Gerlach D, Marszalek JR, et al. BI-3406, a potent and selective SOS1-KRAS interaction inhibitor, is effective in KRAS-driven cancers through combined MEK inhibition. Cancer Discov. 2021;11:142-57.

81. Li W, Nishimura R, Kashishian A, Batzer AG, Kim WJ, Cooper JA, et al. A new function for a phosphotyrosine phosphatase: linking GRB2-Sos to a receptor tyrosine kinase. Mol Cell Biol. 1994;14:509-17.

82. Bennett AM, Tang TL, Sugimoto S, Walsh CT, Neel BG. Protein-tyrosinephosphatase SHPTP2 couples platelet-derived growth factor receptor beta to Ras. Proc Natl Acad Sci U S A. 1994;91:7335-9.
83. Chen X, Zou F, Hu Z, Du G, Yu P, Wang W, et al. PCC0208023, a potent SHP2 allosteric inhibitor, imparts an antitumor effect against KRAS mutant colorectal cancer. Toxicol Appl Pharmacol. 2020;398:115019.

84. Wong GS, Zhou J, Liu JB, Wu Z, Xu X, Li T, et al. Targeting wild-type KRAS-amplified gastroesophageal cancer through combined MEK and SHP2 inhibition. Nat Med. 2018;24:968-77.

85. Fedele C, Ran H, Diskin B, Wei W, Jen J, Geer MJ, et al. SHP2 inhibition prevents adaptive resistance to MEK inhibitors in multiple Cancer models. Cancer Discov. 2018;8:1237-49.

86. Lu H, Liu C, Velazquez R, Wang H, Dunkl LM, Kazic-Legueux M, et al. SHP2 inhibition overcomes RTK-mediated pathway reactivation in KRAS-mutant tumors treated with MEK inhibitors. Mol Cancer Ther. 2019;18:1323-34.

87. Liu C, Lu H, Wang H, Loo A, Zhang X, Yang G, et al. Combinations with allosteric SHP2 inhibitor TNO155 to block receptor tyrosine kinase signaling. Clin Cancer Res. 2021;27:342-54.

88. Quintana E, Schulze CJ, Myers DR, Choy TJ, Mordec K, Wildes D, et al. Allosteric inhibition of SHP2 stimulates antitumor immunity by transforming the immunosuppressive environment. Cancer Res. 2020;80:2889-902.

89. End DW, Smets G, Todd AV, Applegate TL, Fuery CJ, Angibaud P, et al. Characterization of the antitumor effects of the selective farnesyl protein transferase inhibitor R115777 in vivo and in vitro. Cancer Res. 2001;61:131-7.

90. Whitehead RP, McCoy S, Macdonald JS, Rivkin SE, Neubauer MA, Dakhil SR, et al. Phase II trial of R115777 (NSC \#70818) in patients with advanced colorectal cancer: a southwest oncology group study. Investig New Drugs. 2006;24:335-41.

91. Rao S, Cunningham D, de Gramont A, Scheithauer W, Smakal M, Humblet $Y$, et al. Phase III double-blind placebo-controlled study of farnesyl transferase inhibitor R115777 in patients with refractory advanced colorectal cancer. J Clin Oncol. 2004;22:3950-7.

92. Winter-Vann AM, Baron RA. Wong W, dela Cruz J, York JD, Gooden DM, Bergo MO, Young SG, Toone EJ, Casey PJ: a small-molecule inhibitor of isoprenylcysteine carboxyl methyltransferase with antitumor activity in cancer cells. Proc Natl Acad Sci U S A. 2005;102:4336-41.

93. Marín-Ramos NI, Balabasquer M, Ortega-Nogales FJ, Torrecillas IR, Gil-Ordóñez A, Marcos-Ramiro B, et al. A potent Isoprenylcysteine Carboxylmethyltransferase (ICMT) inhibitor improves survival in Ras-driven acute myeloid leukemia. J Med Chem. 2019;62:6035-46.

94. Chandra A, Grecco HE, Pisupati V, Perera D, Cassidy L, Skoulidis F, et al. The GDI-like solubilizing factor PDE $\delta$ sustains the spatial organization and signalling of Ras family proteins. Nat Cell Biol. 2011;14:148-58.

95. Zimmermann G, Papke B, Ismail S, Vartak N, Chandra A, Hoffmann M, et al. Small molecule inhibition of the KRAS-PDE $\delta$ interaction impairs oncogenic KRAS signalling. Nature. 2013;497:638-42.

96. Klein CH, Truxius DC, Vogel HA, Harizanova J, Murarka S, Martín-Gago P, et al. PDES inhibition impedes the proliferation and survival of human colorectal cancer cell lines harboring oncogenic KRas. Int J Cancer. 2019;144:767-76.

97. Martín-Gago P, Fansa EK, Klein CH, Murarka S, Janning P, Schürmann M, et al. A PDE6 $\delta$-KRas inhibitor Chemotype with up to seven $\mathrm{H}$-bonds and Picomolar affinity that prevents efficient inhibitor release by $\mathrm{Arl} 2$ Angew Chem Int Ed Eng. 2017;56:2423-8.

98. Cheng J, Li Y, Wang X, Dong G, Sheng C. Discovery of novel PDES degraders for the treatment of KRAS mutant colorectal Cancer. J Med Chem. 2020;63:7892-905.

99. Fang JY, Richardson BC. The MAPK signalling pathways and colorectal cancer. Lancet Oncol. 2005;6:322-7.

100. Roskoski R Jr. ERK1/2 MAP kinases: structure, function, and regulation. Pharmacol Res. 2012;66:105-43.

101. Peng SB, Henry JR, Kaufman MD, Lu WP, Smith BD, Vogeti S, et al. Inhibition of RAF isoforms and active dimers by LY3009120 leads to anti-tumor activities in RAS or BRAF mutant cancers. Cancer Cell. 2015;28:384-98.

102. Vakana E, Pratt S, Blosser W, Dowless M, Simpson N, Yuan XJ, et al. LY3009120, a panRAF inhibitor, has significant anti-tumor activity in BRAF and KRAS mutant preclinical models of colorectal cancer. Oncotarget. 2017;8:9251-66.

103. Yao YM, Donoho GP, Iversen PW, Zhang Y, Van Horn RD, Forest A, et al. Mouse PDX trial suggests synergy of concurrent inhibition of RAF and 
EGFR in colorectal Cancer with BRAF or KRAS mutations. Clin Cancer Res. 2017;23:5547-60.

104. Sullivan RJ, Hollebecque A, Flaherty KT, Shapiro Gl, Rodon Ahnert J, Millward MJ, et al. A phase I study of LY3009120, a Pan-RAF inhibitor in patients with advanced or metastatic Cancer. Mol Cancer Ther. 2020;19:460-7.

105. Desai J, Gan H, Barrow C, Jameson M, Atkinson V, Haydon A, et al. Phase I, open-label, dose-escalation/dose-expansion study of Lifirafenib (BGB283), an RAF family kinase inhibitor, in patients with solid tumors. J Clin Oncol. 2020;38:2140-50.

106. Zimmer L, Barlesi F, Martinez-Garcia M, Dieras V, Schellens JH, Spano JP, et al. Phase I expansion and pharmacodynamic study of the oral MEK inhibitor RO4987655 (CH4987655) in selected patients with advanced cancer with RAS-RAF mutations. Clin Cancer Res. 2014;20:4251-61.

107. Blumenschein GR Jr, Smit EF, Planchard D, Kim DW, Cadranel J, De Pas T, et al. A randomized phase II study of the MEK1/MEK2 inhibitor trametinib (GSK1120212) compared with docetaxel in KRASmutant advanced non-small-cell lung cancer (NSCLC)t. Ann Oncol. 2015;26:894-901.

108. Friday BB, Yu C, Dy GK, Smith PD, Wang L, Thibodeau SN, et al. BRAF V600E disrupts AZD6244-induced abrogation of negative feedback pathways between extracellular signal-regulated kinase and Raf proteins. Cancer Res. 2008;68:6145-53.

109. Pratilas CA, Taylor BS, Ye Q, Viale A, Sander C, Solit DB. Rosen N: (V600E) BRAF is associated with disabled feedback inhibition of RAF-MEK signaling and elevated transcriptional output of the pathway. Proc Natl Acad Sci U S A. 2009:106:4519-24.

110. Lamba S, Russo M, Sun C, Lazzari L, Cancelliere C, Grernrum W, et al. RAF suppression synergizes with MEK inhibition in KRAS mutant cancer cells. Cell Rep. 2014;8:1475-83.

111. Yen I, Shanahan F, Merchant M, Orr C, Hunsaker T, Durk M, et al. Pharmacological Induction of RAS-GTP Confers RAF Inhibitor Sensitivity in KRAS Mutant Tumors. Cancer Cell. 2018;34:611-25 e617.

112. Xu H, Zhou S, Xia H, Yu H, Tang Q, Bi F. MEK nuclear localization promotes YAP stability via sequestering $\beta-\operatorname{TrCP}$ in KRAS mutant cancer cells. Cell Death Differ. 2019;26:2400-15.

113. Dai X, Xia H, Zhou S, Tang Q, Bi F. Zoledronic acid enhances the efficacy of the MEK inhibitor trametinib in KRAS mutant cancers. Cancer Lett. 2019:442:202-12.

114. Varga A, Soria JC, Hollebecque A, LoRusso P, Bendell J, Huang SA, et al. A first-in-human phase I study to evaluate the ERK1/2 inhibitor GDC-0994 in patients with advanced solid tumors. Clin Cancer Res. 2020;26:1229-36.

115. Merchant M, Moffat J, Schaefer G, Chan J, Wang X, Orr C, et al. Combined MEK and ERK inhibition overcomes therapy-mediated pathway reactivation in RAS mutant tumors. PLoS One. 2017;12:e0185862.

116. Mallucci L, Wells V. The end of KRAS, and other, cancers? A new way forward. Drug Discov Today. 2014;19:383-7.

117. Hoeflich KP, Merchant M, Orr C, Chan J, Den Otter D, Berry L, et al. Intermittent administration of MEK inhibitor GDC-0973 plus PI3K inhibitor GDC-0941 triggers robust apoptosis and tumor growth inhibition. Cancer Res. 2012;72:210-9.

118. Köhler J, Zhao Y, Li J, Gokhale PC, Tiv HL, Knott AR et al. ERK inhibito LY3214996-based treatment strategies for RAS-driven lung Cancer. Mol Cancer Ther. 2021;20:641-54.

119. Martinelli E, Troiani T, D'Aiuto E, Morgillo F, Vitagliano D, Capasso A, et al. Antitumor activity of pimasertib, a selective MEK $1 / 2$ inhibitor, in combination with PI3K/mTOR inhibitors or with multi-targeted kinase inhibitors in pimasertib-resistant human lung and colorectal cancer cells. Int J Cancer. 2013;133:2089-101.

120. Do K, Speranza G, Bishop R, Khin S, Rubinstein L, Kinders RJ, et al. Biomarker-driven phase 2 study of MK-2206 and selumetinib (AZD6244, ARRY-142886) in patients with colorectal cancer. Investig New Drugs. 2015:33:720-8.
121. Shapiro Gl, LoRusso P, Kwak E, Pandya S, Rudin CM, Kurkjian C, et al. Phase Ib study of the MEK inhibitor cobimetinib (GDC-0973) in combination with the PI3K inhibitor pictilisib (GDC-0941) in patients with advanced solid tumors. Investig New Drugs. 2020;38:419-32.

122. Ramanathan RK, Von Hoff DD, Eskens F, Blumenschein G Jr, Richards D, Genvresse I, et al. Phase Ib trial of the PI3K inhibitor Copanlisib combined with the allosteric MEK inhibitor Refametinib in patients with advanced Cancer. Target Oncol. 2020;15:163-74.

123. Tsubaki M, Takeda T, Noguchi M, Jinushi M, Seki S, Morii Y, et al. Overactivation of Akt Contributes to MEK Inhibitor Primary and Acquired Resistance in Colorectal Cancer Cells. Cancers (Basel). 2019;11:1866-84.

124. Wee S, Jagani Z, Xiang KX, Loo A, Dorsch M, Yao YM, et al. PI3K pathway activation mediates resistance to MEK inhibitors in KRAS mutant cancers. Cancer Res. 2009;69:4286-93.

125. Chen DS, Mellman I. Elements of cancer immunity and the cancerimmune set point. Nature. 2017;541:321-30.

126. Alexandrov LB, Nik-Zainal S, Wedge DC, Aparicio SA, Behjati S, Biankin $\mathrm{AV}$, et al. Signatures of mutational processes in human cancer. Nature. 2013;500:415-21.

127. Patnaik A, Kang SP, Rasco D, Papadopoulos KP, Elassaiss-Schaap J, Beeram M, et al. Phase I study of Pembrolizumab (MK-3475; anti-PD-1 monoclonal antibody) in patients with advanced solid tumors. Clin Cancer Res. 2015;21:4286-93.

128. Liu J, Huang $X$, Liu H, Wei C, Ru H, Qin H, et al. Immune landscape and prognostic immune-related genes in KRAS-mutant colorectal cancer patients. J TransI Med. 2021;19:27.

129. Lal N, White BS, Goussous G, Pickles O, Mason MJ, Beggs AD, et al. KRAS mutation and consensus molecular subtypes 2 and 3 are independently associated with reduced immune infiltration and reactivity in colorectal Cancer. Clin Cancer Res. 2018;24:224-33.

130. Poon E, Mullins S, Watkins A, Williams GS, Koopmann JO, Di Genova G, et al. The MEK inhibitor selumetinib complements CTLA-4 blockade by reprogramming the tumor immune microenvironment. J Immunother Cancer. 2017;5:63.

131. Tran E, Robbins PF, Lu YC, Prickett TD, Gartner JJ, Jia L, et al. T-cell transfer therapy targeting mutant KRAS in Cancer. N Engl J Med. 2016;375:2255-62.

132. Veatch JR, Jesernig BL, Kargl J, Fitzgibbon M, Lee SM, Baik C, et al. Endogenous CD4(+) T cells recognize Neoantigens in lung Cancer patients, including recurrent oncogenic KRAS and ERBB2 (Her2) driver mutations. Cancer Immunol Res. 2019;7:910-22.

133. Wang QJ, Yu Z, Griffith K, Hanada K, Restifo NP, Yang JC. Identification of T-cell receptors targeting KRAS-mutated human tumors. Cancer Immunol Res. 2016:4:204-14.

134. Lu Y, Bellgrau D, Dwyer-Nield LD, Malkinson AM, Duke RC, Rodell TC et al. Mutation-selective tumor remission with Ras-targeted, whole yeast-based immunotherapy. Cancer Res. 2004;64:5084-8.

135. Cohn A, Morse MA, O'Neil B, Whiting S, Coeshott C, Ferraro J, et al. Whole recombinant Saccharomyces cerevisiae yeast expressing Ras mutations as treatment for patients with solid tumors bearing Ras mutations: results from a phase 1 trial. J Immunother. 2018:41:141-50

136. Gjertsen MK, Buanes T, Rosseland AR, Bakka A, Gladhaug I, Søreide $\mathrm{O}$, et al. Intradermal ras peptide vaccination with granulocyte-macrophage colony-stimulating factor as adjuvant: clinical and immunological responses in patients with pancreatic adenocarcinoma. Int J Cancer. 2001;92:441-50.

137. Guinney J, Dienstmann R, Wang X, de Reyniès A, Schlicker A, Soneson C, et al. The consensus molecular subtypes of colorectal cancer. Nat Med. 2015;21:1350-6.

\section{Publisher's Note}

Springer Nature remains neutral with regard to jurisdictional claims in published maps and institutional affiliations. 